Universidad de Lima

Facultad de Ciencias Empresariales y Económicas

Carrera de Contabilidad

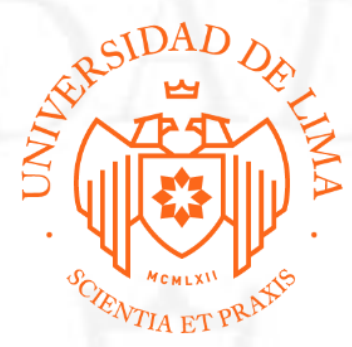

\title{
ANÁLISIS DE LA ADOPCIÓN DE LA NIIF 15 - INGRESOS DE ACTIVIDADES ORDINARIAS DE CONTRATOS CON CLIENTES Y SU IMPACTO EN LA SITUACIÓN FINANCIERA Y RESULTADOS DEL PERIODO. CASO ALICORP S.A.A. - PERIODO 2017
}

Trabajo de suficiencia profesional para optar el Título Profesional de Contador Público

Tania Alessandra Calle Morales

Código 20110216

\author{
Asesor \\ Julio Segundo Catacora Díaz
}

Lima - Perú

Noviembre del 2018 


\section{ANÁLISIS DE LA ADOPCIÓN DE LA NIIF 15 - INGRESOS DE ACTIVIDADES ORDINARIAS DE CONTRATOS CON CLIENTES Y SU IMPACTO EN LA SITUACIÓN FINANCIERA Y RESULTADOS DEL PERIODO. CASO ALICORP S.A.A. - PERIODO 2017}


A mis padres Amparo y Mario, por su incondicional apoyo $\mathrm{y}$ por ser mi fuente de inspiración para culminar este trabajo. 


\section{Tabla de Contenido}

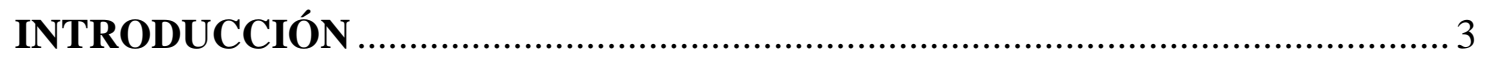

CAPÍTULO I: ANTECEDENTES DE LA ENTIDAD ...................................... 4

1.1. Identificación y actividad económica de la entidad ...................................... 4

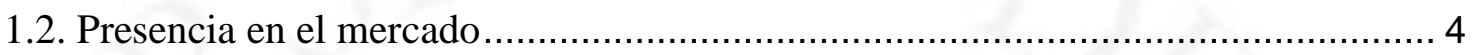

CAPÍTULO II: DESCRIPCIÓN Y OBJETIVOS DEL TRABAJO DE

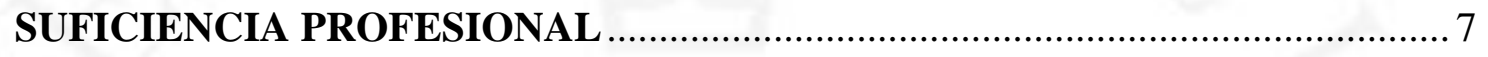

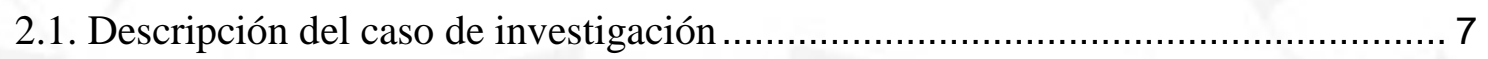

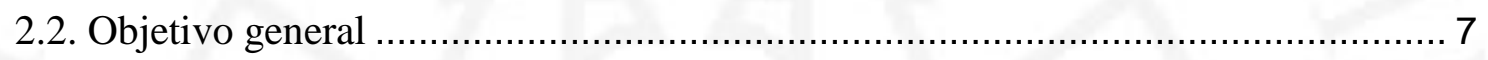

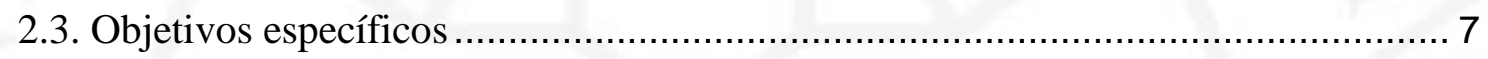

CAPÍTULO III: MARCO METODOLÓGICO ................................................ 9

3.1. Metodología de recolección de la información ......................................... 9

3.2. Metodología de análisis de la información ............................................... 9

CAPÍTULO IV: ANÁLISIS, PRESENTACIÓN Y DISCUSIÓN DE

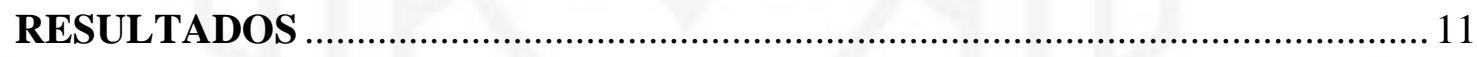

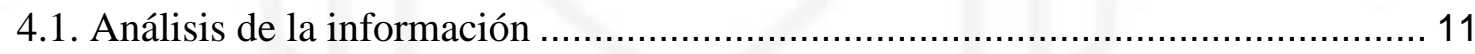

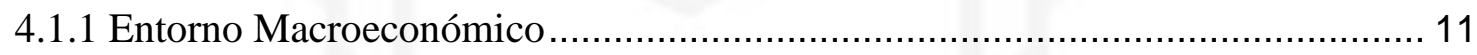

4.1.2 Análisis de los resultados individuales de los periodos 2015 al 2017 de Alicorp

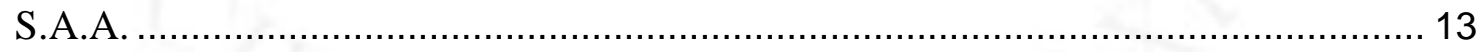

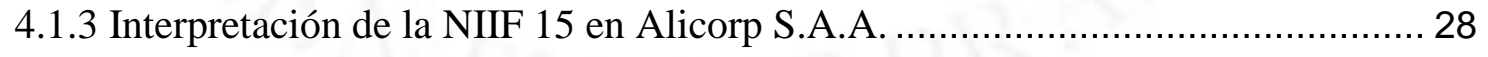

4.2. Presentación y discusión de resultados ................................................... 34

4.2.1 Impacto de la NIIF 15 en el Estado de Resultados de Alicorp S.A.A................ 34

4.2.2 Proyección de los Estados Financieros de Alicorp S.A.A. del 2018 al 2020 ...... 37

4.2.3 Flujo de Caja Proyectado de Alicorp S.A.A. del 2018 al 2020...................... 38 


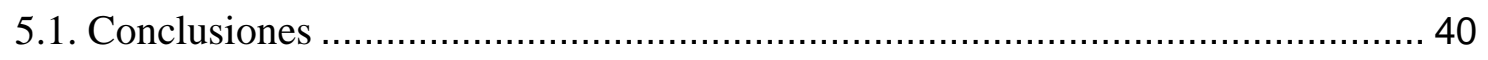

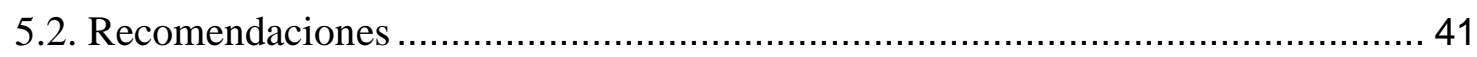

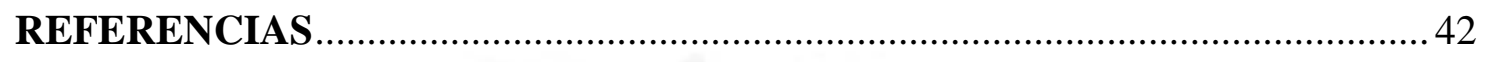

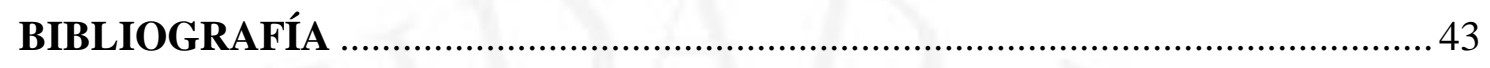

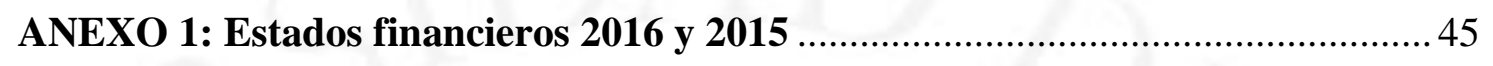

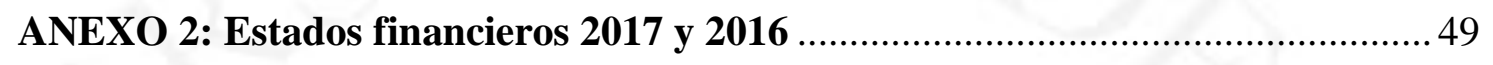

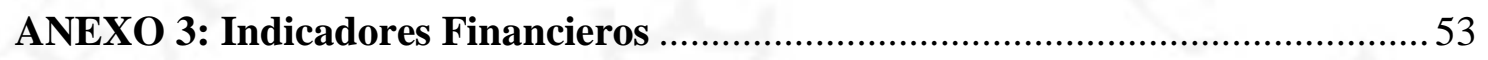

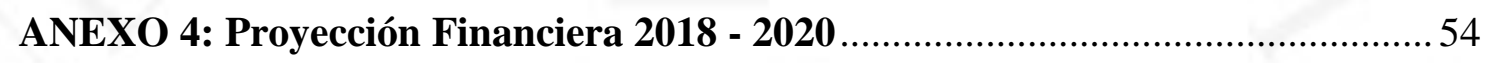

ANEXO 5: Indicadores Financieros de la proyección 2018 al 2020 ......................57

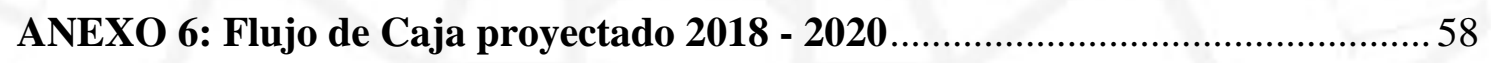




\section{ÍNDICE DE TABLAS}

Tabla 1.1 Principales accionistas ade Alicorp S.A.A. ..................................................4

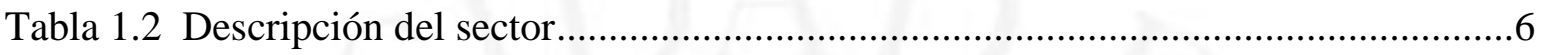

Tabla 4.1 PBI por sectores económicos .................................................................. 12

Tabla 4.2 Índice financiero: Rentabilidad sobre utilidad neta ......................................... 18

Tabla 4.3 Índice financiero: Rotación Liquidez - Caja.....................................................21

Tabla 4.4 Índice financiero: Rotación de cuentas por cobrar ......................................22

Tabla 4.5 Índice financiero: Rotación de inventarios ..................................................23

Tabla 4.6 Índice financiero: Endeudamiento patrimonial ........................................26

Tabla 4.7 Índice financiero: Rentabilidad sobre patrimonio .......................................28

Tabla 4.8 Criterio de contrato identificados en Alicorp S.A.A. .....................................30

Tabla 4.9 Obligaciones de desempeño de la Compañía ..............................................30

Tabla 4.10 Estado de Resultados proyectado 2018 y 2017 ..........................................34

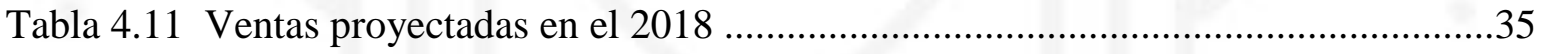

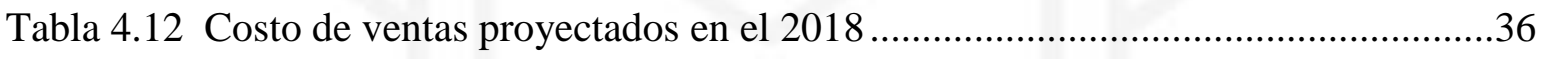




\section{ÍNDICE DE FIGURAS}

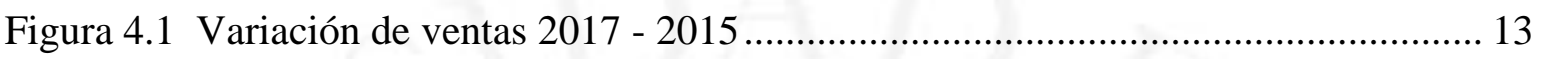

Figura 4.2 Variación del volumen vendido 2017 - 2015 .......................................... 14

Figura 4.3 Variación de la utilidad bruta 2017 - 2015 ............................................... 15

Figura 4.4 Variación de la utilidad operativa 2017 - 2015 ......................................... 16

Figura 4.5 Variación del EBITDA 2017 - 2015 ......................................................... 17

Figura 4.6 Variación de la utilidad neta 2017 - 2015 ................................................ 17

Figura 4.7 Variación de los activos 2017 - 2015 ....................................................... 19

Figura 4.8 Variación de efectivo y equivalente de efectivo 2017 - 2015 ........................ 20

Figura 4.9 Variación de las cuentas por cobrar comerciales 2017 - 2015 ...................... 21

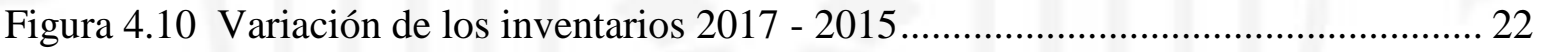

Figura 4.11 Variación de propiedades, planta y equipo 2017 - 2015 ............................. 23

Figura 4.12 Variación de activos intangibles 2017 - 2015 ........................................ 24

Figura 4.13 Variación de pasivos 2017 - 2015 ............................................................... 24

Figura 4.14 Evolución de los pasivos financieros 2017 - 2015 .................................... 26

Figura 4.15 Variación del patrimonio 2017 - 2015 ...................................................... 27 


\section{INTRODUCCIÓN}

A partir del 1 de enero de 2018, entró en vigencia, en nuestro país, la NIIF 15 "Ingresos de Actividades Ordinarias Procedentes de Contratos con Clientes" para las entidades que reportan bajo NIIF. Esta nueva norma trae consigo cambios en el reconocimiento de los ingresos llegando a ser más restrictiva al momento de contabilizarlos, especialmente en cuantos a servicios se refiere. Asimismo, deroga todas las normas anteriores relacionadas al reconocimiento de ingresos; entre ellas a la NIC 18 "Ingresos de actividades ordinaria" y a la NIC 11 "Contrato de construcción”.

De esta manera, es necesario que la entidad realice una evaluación para identificar y determinar previamente las medidas y posteriormente, el plan de implementación que será necesario ejecutar con la finalidad de adecuarse a las nuevas exigencias de esta norma. Por este motivo, se establecerá los principios que se aplicarán para presentar información relevante a los usuarios de los estados financieros acerca de los ingresos de las actividades ordinarias que se origina a través de los contratos con los clientes.

En la presente investigación se analizará el caso de la empresa Alicorp S.A.A. quien a partir del presente año tiene la obligatoriedad de implementar esta nueva norma, por lo que durante el año 2017 ha realizado una evaluación de los impactos en la situación financiera y resultados del periodo. Se identificarán los cambios que supondrán en los estados financieros del periodo 2017 y se realizara una proyección con la implementación de la NIIF 15 desde el año 2017 al 2020.

Es importante entender cuáles son los cambios significativos de la contabilidad de los ingresos según la NIIF 15 y contrastarlo, principalmente, con la NIC 18 y la NIC 11, con la finalidad de analizar y evaluar los efectos contables que tendrá en los estados financieros de la entidad. 


\section{CAPÍTULO I: ANTECEDENTES DE LA ENTIDAD}

\subsection{Identificación y actividad económica de la entidad}

Alicorp S.A.A fue constituida en el Perú e inicio sus operaciones en el año 1956 bajo el nombre de Anderson, Clayton \& Co. En 1971, el Grupo Romero la adquirió y posteriormente en el año 1997, tras fusionarse con Nicolini Hermanos S.A. y Compañía Molinera del Perú S.A., cambio su denominación a Alicorp S.A.A. El domicilio legal se encuentra en la Av. Argentina $N^{\circ}$ 4793, Carmen de la Legua-Reynoso, Callao, Perú.

Alicorp S.A.A.es una Sociedad Anónima Abierta que cuenta al 31 de diciembre del 2017 con 1,409 accionistas comunes. Los accionistas que son titulares al 31 de diciembre del 2017 de más del 5\% del capital suscrito y pagado de la sociedad son los siguientes:

\section{Tabla 1.1}

Principales accionistas de Alicorp S.A.A.

\begin{tabular}{|l|c|c|c|c|}
\hline \multicolumn{1}{|c|}{ Accionista Económico } & Saldo & $\mathbf{( \% )}$ & Nacionalidad & Grupo Económico \\
\hline $\begin{array}{l}\text { Birmingham Merchant } \\
\text { S.A. }\end{array}$ & $93,547,435$ & $11.04 \%$ & Panameña & - \\
\hline AFP Integra S.A. & $89,508,199$ & $9.86 \%$ & Peruana & $\begin{array}{c}\text { Grupo Inversiones } \\
\text { Suramericana }\end{array}$ \\
\hline $\begin{array}{l}\text { Grupo Piurano de } \\
\text { Inversiones S.A. }\end{array}$ & $66,001,799$ & $7.79 \%$ & Peruana & Grupo Romero \\
\hline Prima AFP & $65,422,591$ & $7.72 \%$ & Peruana & Credicorp Ltd. \\
\hline Profuturo AFP & $62,037,974$ & $7.32 \%$ & Peruana & $\begin{array}{c}\text { The Bank of Nova } \\
\text { Scotia }\end{array}$ \\
\hline Atlantic Security Bank & $46,248,896$ & $5.10 \%$ & Gran Caimán & Credicorp Ltd. \\
\hline
\end{tabular}

Fuente: Alicorp (2018).

Las acciones comunes y de inversión de Alicorp S.A.A. se encuentran listadas en la Bolsa de Valores de Lima bajo los símbolos de ALICORC1 y ALICORI1, respectivamente.

\subsection{Presencia en el mercado}

Alicorp S.A.A. es una compañía de consumo masivo líder en el mercado peruano, con operaciones industriales en seis países de Latinoamérica: Argentina, Brasil, Chile, Colombia, 
Ecuador y Perú, donde se encuentra su sede principal. Además, realiza exportaciones de sus productos a países como: Bolivia, Chile, Ecuador, Haití, Colombia, Reino Unido, entre otros. Es la segunda empresa de consumo masivo más grande de los Andes.

La actividad económica de la compañía consiste en la producción y distribución de productos principalmente alimenticios y de limpieza, principalmente aceites y grasas comestibles, fideos, harinas, galletas, detergentes, salsas, panetones, cereales entre otros; así como la distribución de productos fabricados por terceros.

Asimismo, ofrece prestación de toda clase de servicios y asesoramiento industrial, comercial y administrativo en sus diversas áreas; así como actividades de desmote y comercialización de algodón, semillas oleaginosas y subproductos derivados de los mismos.

Alicorp S.A.A. gestiona principalmente dos líneas de negocio:

a) Consumo masivo. Dentro se encuentran las siguientes divisiones:

- Oleaginosos: Margarinas y aceite domésticos, conserva de pescado.

- Lavandería: Detergentes, jabones, suavizantes, etc.

- Farináceos: Fideos, harinas domésticas, cereales, etc.

- Salsas

- Impulso: Galletas, golosinas, panetones.

- Instantáneos: Refrescos, postres.

b) B2B (Business to business), se refiere al modelo de negocio en el que la transacción de bienes se produce entre 2 empresas. Se encuentran las siguientes divisiones:

- Panificación: Harinas, mantecas industriales, pre mezclas, etc.

- Gastronomía: Aceites, salsas, congelados, etc.

- Industrias: Aceites, harinas industriales, etc.

Además, cuenta con más de 125 marcas líderes en los mercados de consumo masivo, productos industriales y nutrición animal.

En la siguiente tabla se puede explicar la participación de mercado Alicorp en las siguientes categorías: 
Tabla 1.2

Descripción del sector

\begin{tabular}{|c|c|c|c|c|c|c|}
\hline \multirow{2}{*}{$\begin{array}{l}\text { Participación de mercado Alicorp en } \\
\text { las categorías }(\%) \text { : }\end{array}$} & \multicolumn{3}{|c|}{ VOLUMEN } & \multicolumn{3}{|c|}{ VALOR } \\
\hline & 2016 & 2017 & Dif. pp. & 2016 & 2017 & Dif. pp. \\
\hline \multicolumn{7}{|l|}{ Oleaginosos } \\
\hline Aceites Domésticos (con maquilas) & 58.9 & 57.5 & -1.4 & 61.1 & 60.5 & -0.6 \\
\hline Aceites Domésticos (sin maquilas) & 50.9 & 48.4 & -2.5 & 55.1 & 53.5 & -1.6 \\
\hline Margarinas Domésticas & 65.7 & 65.9 & +0.2 & 64.4 & 64.8 & +0.4 \\
\hline Conservas de Pescado & - & 3.0 & +3.0 & - & 3.9 & +3.9 \\
\hline Conservas de Atún & - & 5.6 & +5.6 & - & 6.2 & +6.2 \\
\hline \multicolumn{7}{|l|}{ Lavandería } \\
\hline Detergentes & 58.3 & 58.4 & +0.1 & 58.4 & 59.8 & +1.4 \\
\hline Jabón de Lavar & 81.1 & 78.3 & -2.8 & 84.4 & 82.4 & -2.0 \\
\hline Suavizantes & 16.8 & 21.1 & +4.3 & 17.2 & 21.2 & +4.0 \\
\hline Quitamanchas & 1.1 & 9.4 & +8.3 & 1.8 & 12.1 & +10.3 \\
\hline \multicolumn{7}{|l|}{ Farináceos } \\
\hline Fideos & 50.1 & 49.5 & -0.6 & 54.5 & 54.4 & -0.1 \\
\hline Harinas Domésticas & 43.0 & 42.4 & -0.6 & 54.0 & 53.8 & -0.2 \\
\hline Cereales & 75.2 & 76.8 & +1.6 & 70.0 & 71.9 & +1.9 \\
\hline Premezclas & 82.0 & 84.2 & +2.2 & 66.8 & 71.0 & +4.2 \\
\hline \multicolumn{7}{|l|}{ Salsas } \\
\hline Mayonesa & 94.9 & 94.2 & -0.7 & 96.6 & 96.0 & -0.6 \\
\hline Ketchup & 45.7 & 50.2 & +4.5 & 51.0 & 55.1 & +4.1 \\
\hline Picantes & 98.8 & 97.6 & -1.2 & 99.1 & 98.2 & -0.9 \\
\hline Salsas Rojas & 30.4 & 29.3 & -1.1 & 28.6 & 27.0 & -1.6 \\
\hline \multicolumn{7}{|l|}{ Impulso } \\
\hline Galletas & 33.7 & 32.9 & -0.8 & 31.1 & 30.0 & -0.9 \\
\hline Panetones & 8.6 & 9.5 & +0.9 & 9.3 & 12.3 & +3 \\
\hline \multicolumn{7}{|l|}{ Instantáneos } \\
\hline Refrescos Instantáneos & 69.6 & 66.4 & -3.2 & 63.2 & 61.2 & -2.0 \\
\hline Gelatina & 28.2 & 30.8 & +2.6 & 36.5 & 40.8 & +4.3 \\
\hline Mazamorra & 78.3 & 77.7 & -0.6 & 80.8 & 80.8 & 0.0 \\
\hline
\end{tabular}

Fuente: Alicorp (2018). 


\section{CAPÍTULO II: DESCRIPCIÓN Y OBJETIVOS DEL TRABAJO DE SUFICIENCIA PROFESIONAL}

\subsection{Descripción del caso de investigación}

El presente trabajo de investigación estará centrado en la implementación de la NIIF 15 Ingresos de actividades ordinarias de contratos con clientes y su impacto en la situación financiera de Alicorp S.A.A. mediante el análisis de la información financiera. Para llevarlo a cabo, se realizará una proyección de los estados financieros del año 2018 al año 2020 considerando la adopción de la NIIF.

Adicionalmente, se realizará un diagnóstico financiero de Alicorp S.A.A. por el periodo cerrado del 2015 al 2017 con el objetivo de evaluar el estado de viabilidad económica y financiera de la empresa dedicada a la producción y distribución de productos elaborados de aceites y grasas de origen vegetal y animal. De esta manera, se determinará el impacto financiero en los estados financieros producto de la implementación de la NIIF 15.

\subsection{Objetivo general}

La presente investigación busca analizar la adopción de las NIIF 15 - Ingresos de actividades ordinarias de contratos con clientes, con la finalidad de determinar su impacto en la situación financiera y resultados de los periodos proyectados del 2018 al 2020 en Alicorp S.A.A.

\subsection{Objetivos específicos}

Para alcanzar el objetivo general, enunciado en el numeral anterior, se deben lograr los siguientes objetivos específicos: 
- Analizar la información financiera para ver el desempeño de la empresa Alicorp S.A.A del periodo 2015 al 2017.

- Identificar los cincos pasos del modelo de la NIIF 15 y aplicarlos en la empresa Alicorp S.A.A

- Estructurar el impacto financiero para Alicorp S.A.A. por la adopción de la NIIF 15 a través de la proyección financiera desde el año 2018 hasta el 2020. 


\section{CAPÍTULO III: MARCO METODOLÓGICO}

\subsection{Metodología de recolección de la información}

En el proceso de investigación, la información fue recolectada de los estados financieros auditados de Alicorp S.A.A. por los años 2017 y 2016, reportes anuales de los años 2017, 2016 y 2015, bibliografía relacionada a las Normas Internacionales de Información Financiera, principalmente la NIIF 15 y NIC 18 con la finalidad de realizar una evaluación de los impactos de las mismas y que serán de relevancia para la misma empresa.

Se aplicaron las siguientes técnicas:

- Identificación: técnica que consiste en la lectura fija e interesada y análisis para mantenerse en contacto con el objeto identificado.

- Recopilación documentaria: consistió en la obtención de todos los documentos que traten del tema que se va a analizar.

- Análisis documentario: herramienta que permitió estudiar la NIIF 15 así como tesis relacionadas a la norma, estados financieros auditados, libros, artículos de Internet y otras fuentes documentales.

\subsection{Metodología de análisis de la información}

Para la realización de la presente investigación se siguieron las siguientes acciones:

- Se seleccionó el caso de estudio y la compañía a analizar.

- Obtención de información de libros, artículos de internet, entre otros documentos.

- Evaluación de la situación anterior y posterior de la implementación de la NIIF 15 en la empresa Alicorp S.A.A. 
- La obtención de la información y datos proporcionados mediante la técnica de las entrevistas a especialistas y del análisis de los documentos obtenidos.

- Análisis del impacto de la NIIF 15 en la empresa Alicorp mediante la elaboración de la proyección financiera desde el año 2017 hasta el 2020.

- Elaboración de las conclusiones y posteriores recomendaciones respecto a los objetivos que se determinaron en el presente trabajo de investigación y presentación de resultados. 


\section{CAPÍTULO IV: ANÁLISIS Y PRESENTACIÓN Y DISCUSIÓN DE RESULTADOS}

\subsection{Análisis de la información}

\subsubsection{Entorno Macroeconómico}

En el año 2015, la producción manufacturera no primaria disminuyó 2.6 por ciento, esto se debe a caídas en las exportaciones, así como producción de insumos y bienes de capital. Al año siguiente, los sectores no primarios crecieron en un 0,6 y estuvieron afectados principalmente por una débil demanda interna. Ello se tradujo en tasas negativas de crecimiento en este sector, así como en el de construcción.

Por su parte, en el año 2017 hubo una mejora del 1.1 por ciento puesto que hubo más producción de bienes orientados a insumos, consumo masivo y exportaciones.

Asimismo, de acuerdo con el Banco Central de Reserva del Peru (BCRP, 2018):

El primer semestre de 2018, la manufactura no primaria creció 4,4 \% en el primer semestre de 2018 por lo que hubo una recuperación del PBI. Dentro de los sectores no primarios, destaca el crecimiento del sector servicios (4,6 ciento), el crecimiento del sector construcción (6,1 por ciento) y la recuperación de la manufactura no primaria. (p. 61) 
Tabla 4.1

PBI por sectores económicos

\begin{tabular}{|lcccc|}
\hline \multicolumn{5}{c}{ PBI por sectores económicos } \\
(variaciones porcentuales reales)
\end{tabular}

Fuente: Banco Central de Reserva del Peru, BCRP (2018)

En cuanto a los aspectos comerciales, Equilibrium Clasificadora de Riesgo S.A. (2018), menciona lo siguiente:

Al finalizar el primer trimestre de 2018, las ventas anuales consolidadas muestran que Alicorp lidera todas las categorías de productos en los segmentos de negocio de Consumo Masivo Perú y B2B. Alicorp compite con compañías globales y regionales como Procter\&Gamble, Unilever, Mondelez, Nestlé, Carozzi, entre otras.

Alicorp S.A.A. lleva a cabo sus operaciones en una industria altamente competitiva por lo que se basa en el precio. Por este motivo, la compañía trabaja constantemente para mejorar la calidad de sus productos para que así pueda ganar una mayor participación en el mercado desarrollando estrategias eficaces y reforzando su relación con los consumidores y clientes finales.

Alicorp S.A.A. es uno de los principales compradores de materia primas. Como ejemplo podemos mencionar la compra del trigo, crudo de soya, harina de pescado, aceites 
vegetales, entre otros. Además, utiliza grandes cantidades de plásticos y cartón para empacar sus productos, y gas natural para sus fábricas y almacenes.

Por otro lado, existen factores externos que están fuera de control de la compañía como las condiciones económicas en el país, fluctuaciones monetarias, la demanda, cambios en programas gubernamentales que pueden ocasionar que los precios de los commodities suban o bajen de un momento a otro. Es por esto que, en la actualidad, la compañía tiene una estrategia de cobertura de commodities para lograr disminuir el riesgo ante el aumento o baja de los precios de estos.

\subsubsection{Análisis de los resultados individuales de los periodos 2015 al 2017 de Alicorp}

\section{S.A.A.}

\section{Estado de Resultados}

\section{Ventas}

Figura 4.1

Variación de ventas 2017 - 2015

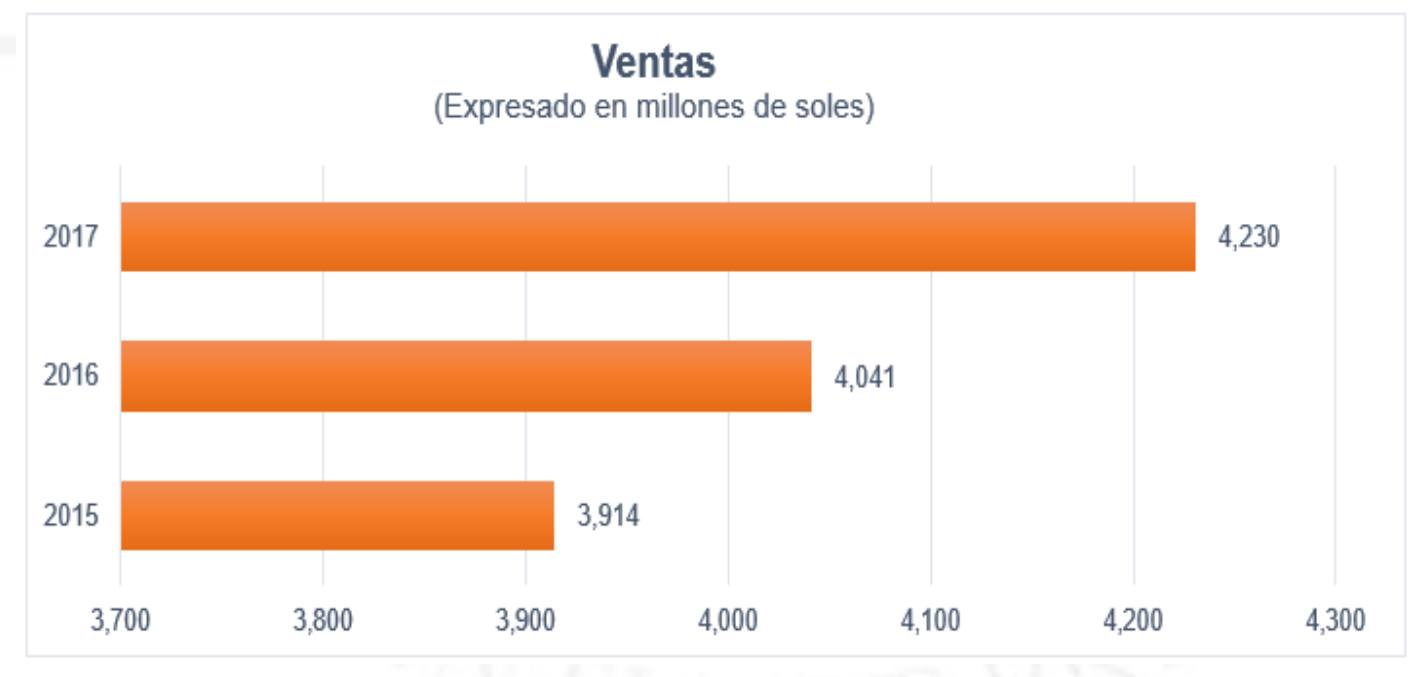

Elaboración propia.

En el año 2016 las ventas alcanzaron los S/4,040.7 millones, lo que representa un incremento de $3.24 \%$ en comparación a las ventas del 2015 (Ver anexo 1).

Asimismo, durante el año 2017, las ventas alcanzaron los S/ 4,230.3 millones, mayor valor de ventas obtenido en el año 2016 (con una variación de 4.6\% con respecto al año anterior). 
(Ver anexo 2). La obtención del mayor incremento en $4.69 \%$ corresponden a un efecto neto de: i) mayor venta en el negocio de Consumo Masivo con S/141.1 millones (incremento de 5.5\% versus 2016) debido al ingreso en la nueva categoría de conservas y al crecimiento en las categorías principales. Un ejemplo es en la industria de Oleaginosas donde se encuentran las marcas premium como Primor, Capri y Cocinero. ii) mayor venta en el negocio B2B por S/48.4 millones (disminución de 3\% versus el 2016). El mayor volumen de 2\%, se explica por las ventas con respecto al año 2016 en los negocios de Consumo Masivo y B2B, respectivamente.

Figura 4.2

Variación del volumen vendido 2017 - 2015

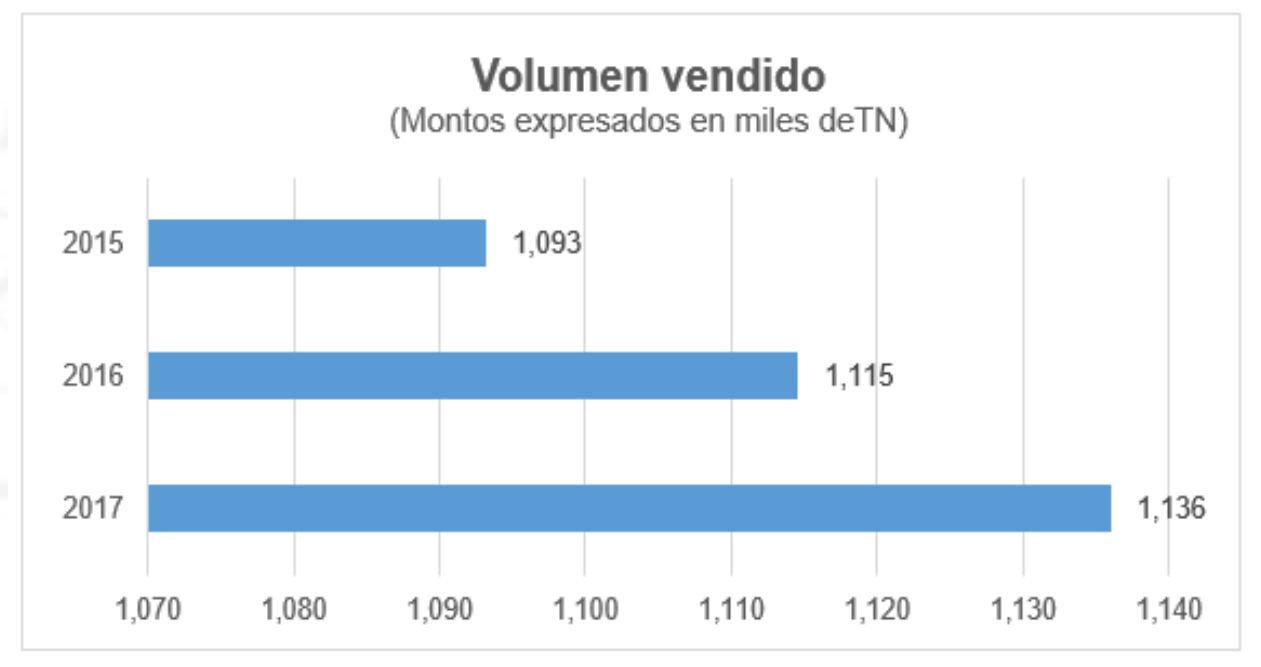

Elaboración propia.

El volumen de ventas alcanzó las 1,114.6 miles de toneladas en el año 2016 y 1,093.2 miles de toneladas en el 2015. En el año 2017, el volumen de ventas alcanzó las 1,136 mil toneladas. 


\section{Utilidad Bruta}

Figura 4.3

Variación de la utilidad bruta 2017 - 2015

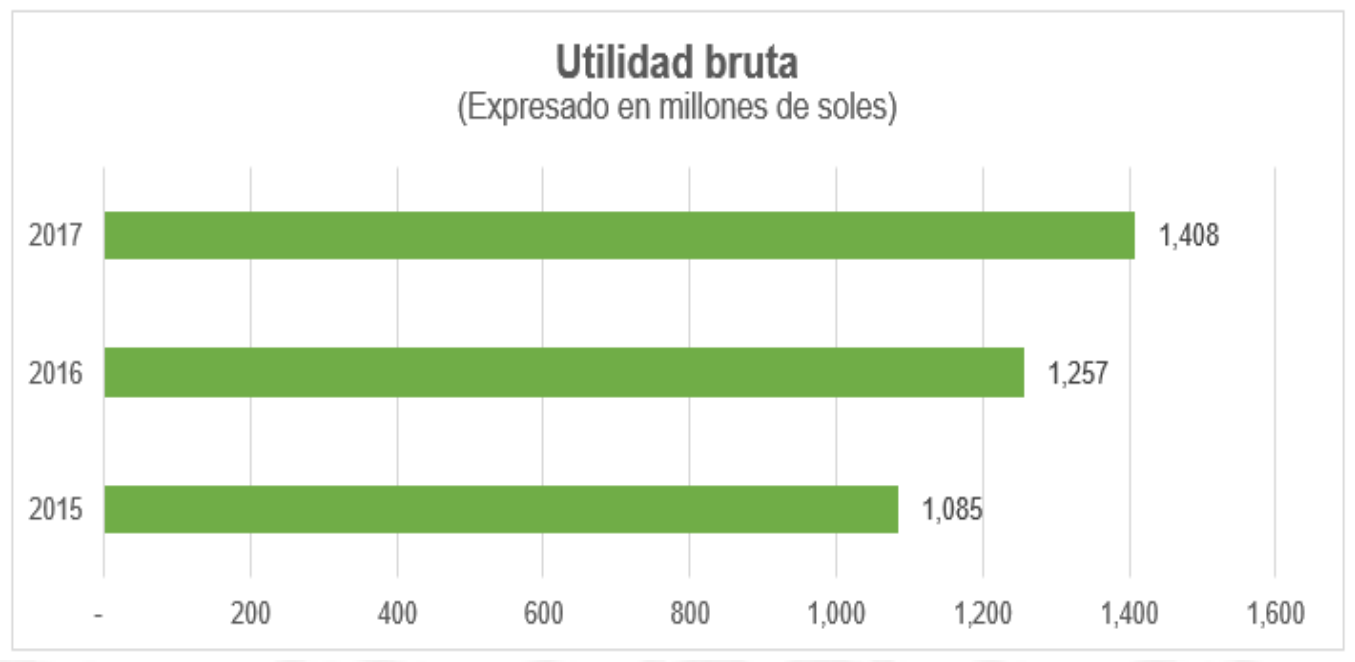

Elaboración propia.

La utilidad bruta durante el 2016 fue de 1,257.0 millones, 15.8\% mayor a la obtenida en el año 2015. El margen bruto se incrementó a 31.1\% en comparación con el $27.7 \%$ del 2015. En el 2017 fue de S/ 1,408.2 millones, 12.02\% mayor a la obtenida al año anterior. El margen bruto se incrementó a 33.3\% en comparación con el 31.1\% del 2016.

El incremento del año 2015 al 2017 se explica principalmente por:

i) Una adecuada gestión de ingresos y menores precios de materias primas en el negocio de Consumo Masivo con un incremento de $11.5 \%$,

ii) Una mayor contribución operativa de la plataforma Food Service en el negocio de $\mathrm{B} 2 \mathrm{~B}$ con un incremento de $10.9 \%$, y

iii) Ahorros en los procesos de compras y producción como resultado del programa de eficiencias. 


\section{Utilidad Operativa y EBITDA}

Figura 4.4

Variación de la utilidad operativa 2017 - 2015

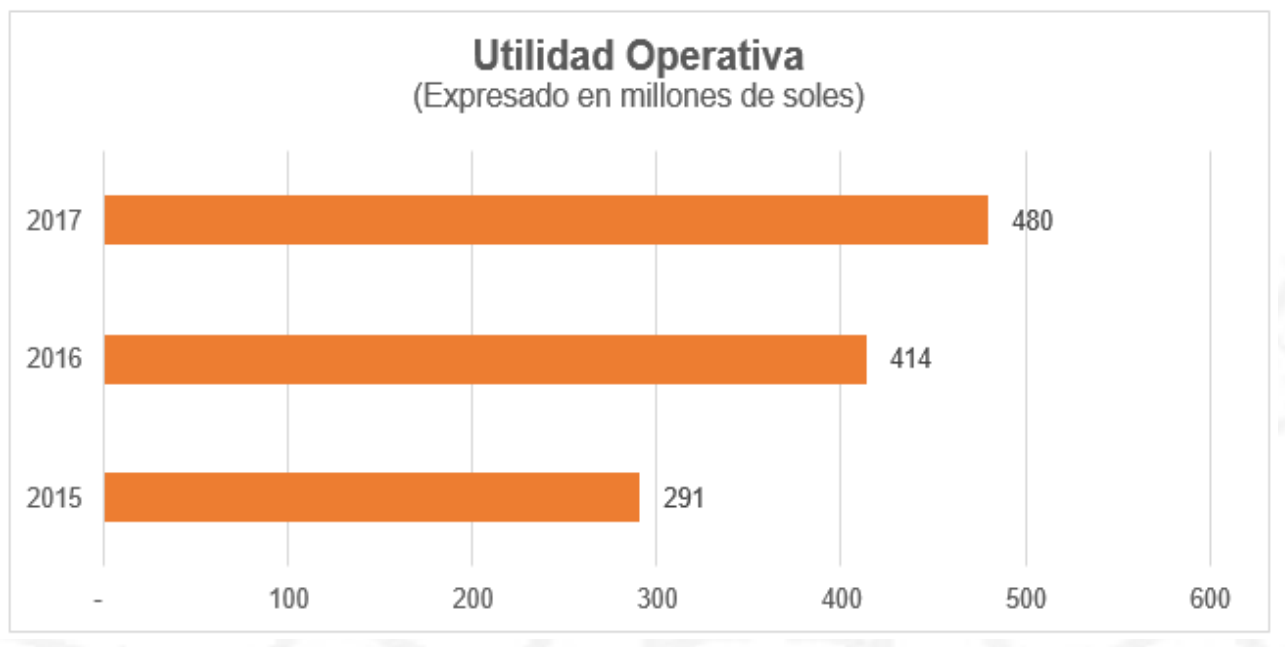

Elaboración propia.

La utilidad operativa del 2016, alcanzo los S/413.6 millones (10.2\% de las ventas netas), 42.2\% mayor a la utilidad operativa obtenida en el 2015. Asimismo, la utilidad operativa del 2017 alcanzó los S/ 479.8 millones (11.3\% de las ventas netas), 15.9\% mayor a la utilidad operativa obtenida en el año anterior.

Este aumento se explica por un mayor margen bruto compensados con el incremento principalmente de los gastos de venta y distribución, explicados por mayor inversión comercial en los canales de venta, publicidad y promociones.

La utilidad antes de intereses, impuestos, depreciación y amortización (EBITDA), se muestra en el siguiente recuadro: 
Figura 4.5

Variación del EBITDA 2017 - 2015

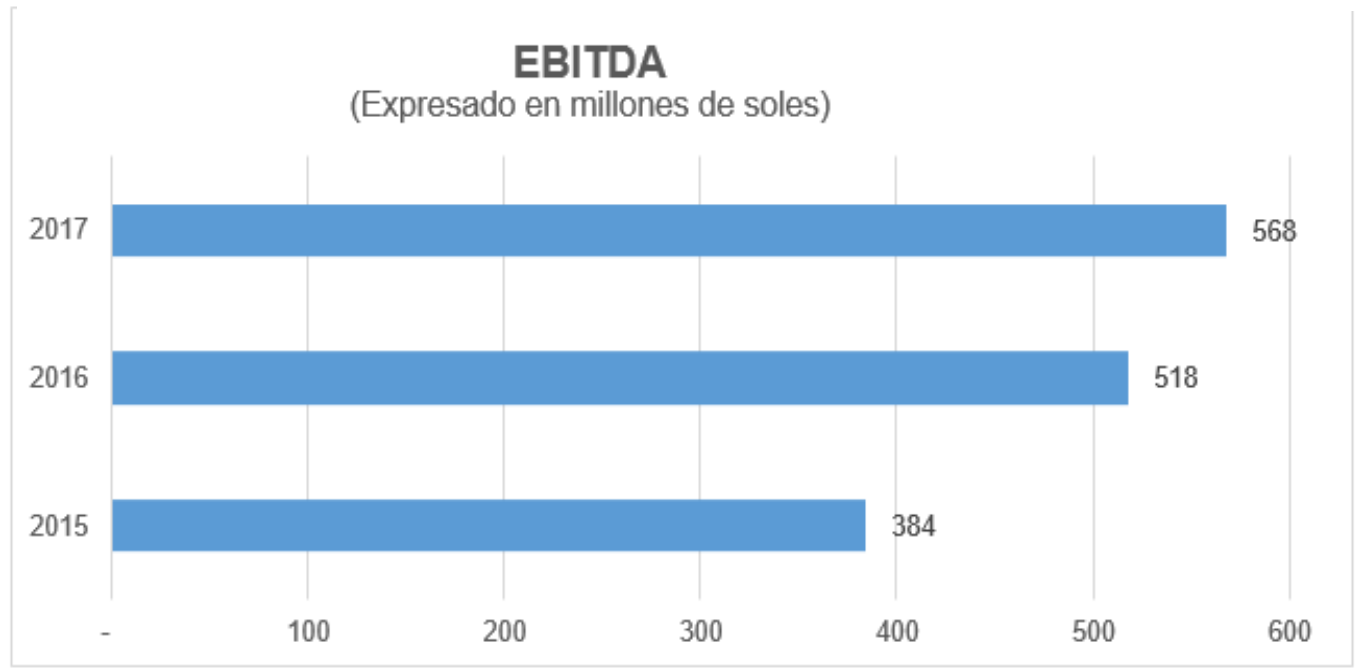

Elaboración propia.

En el año 2015 fue de S/384.5 millones (10.1\% de las ventas netas) y de S/384.5 millones durante el 2016. Por su parte en el 2017, fue de 568.2 millones (13.4\% de las ventas netas). Este incremento es impulsado por una correcta gestión de precios, buena estrategia de adquisición de materia prima a pesar del aumento en los gastos comerciales.

\section{Utilidad Neta}

Figura 4.6

Variación de la utilidad neta 2017 - 2015

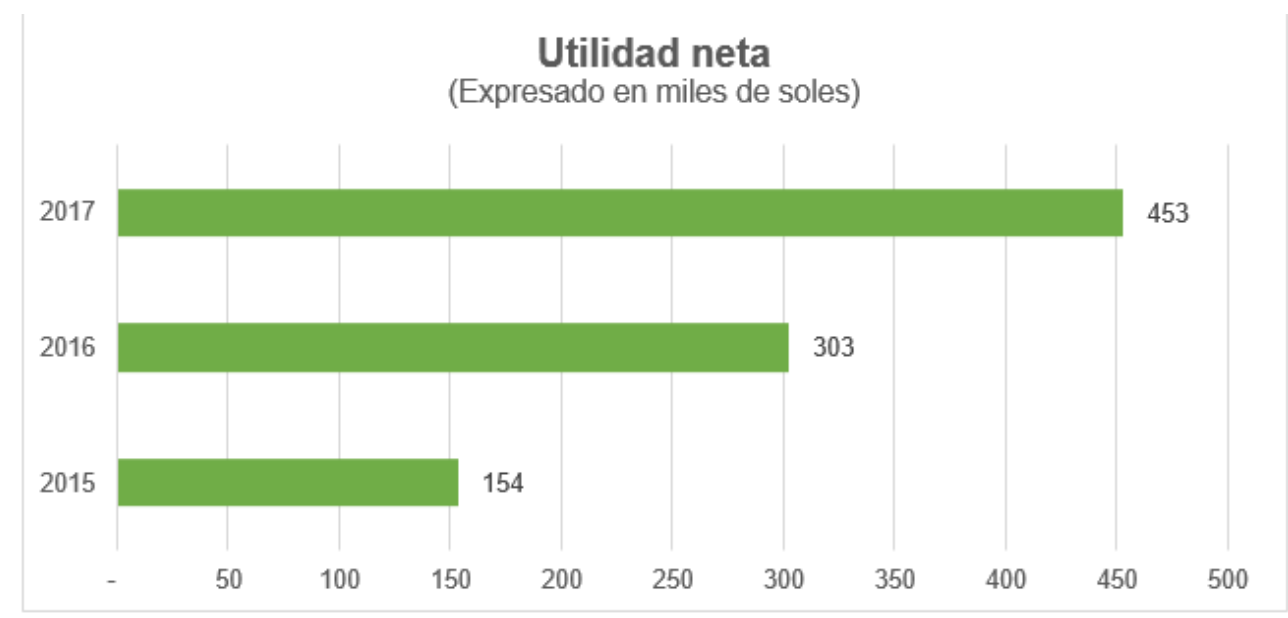

Elaboración propia

La utilidad neta durante el 2015 fue de S/153.6 millones (3.9\% sobre las ventas netas) y en el 2016 fue de S/302.5 millones (7.5\% sobre las ventas netas). Esto se explica por una 
mayor utilidad bruta, menores gastos financieros netos compensados por un mayor impuesto a la renta.

Por su parte la utilidad neta en el 2017 fue de S/ 453.1 millones (10.7\% sobre ventas netas) El incremento en este año se explica principalmente por: i) una mayor utilidad operativa principalmente en el negocio de Consumo Masivo, ii) disminución de gastos financieros netos, iii) menor gasto por impuesto a la renta, compensados con un mayor ingreso por valor de participación patrimonial.

Por otro lado, en el año 2015 la utilidad por acción fue de S/0.180, en el 2016 fue de S/0.354 y en el año 2017, la utilidad por acción fue de S/0.530.

La variación en la rentabilidad neta sobre utilidad neta se muestra a continuación:

\section{Tabla 4.2}

Índice financiero: Rentabilidad sobre utilidad neta

\begin{tabular}{|c|c|c|c|}
\hline Ratio & 2015 & 2016 & 2017 \\
\hline Rentabilidad sobre Utilidad Neta & 0.04 & 0.07 & 0.11 \\
\hline
\end{tabular}

Elaboración propia.

Este indicador es una medida de rentabilidad neta sobre las ventas. A través de los años se ha ido incrementando, teniendo en el año 2017 una rentabilidad de 0.11 . Esto quiere decir que Alicorp S.A.A. viene mejorando su utilidad sin necesidad de incrementar el financiamiento de sus accionistas. 


\section{Estado de Situación Financiera}

\section{Activos}

Figura 4.7

Variación de los activos 2017 - 2015

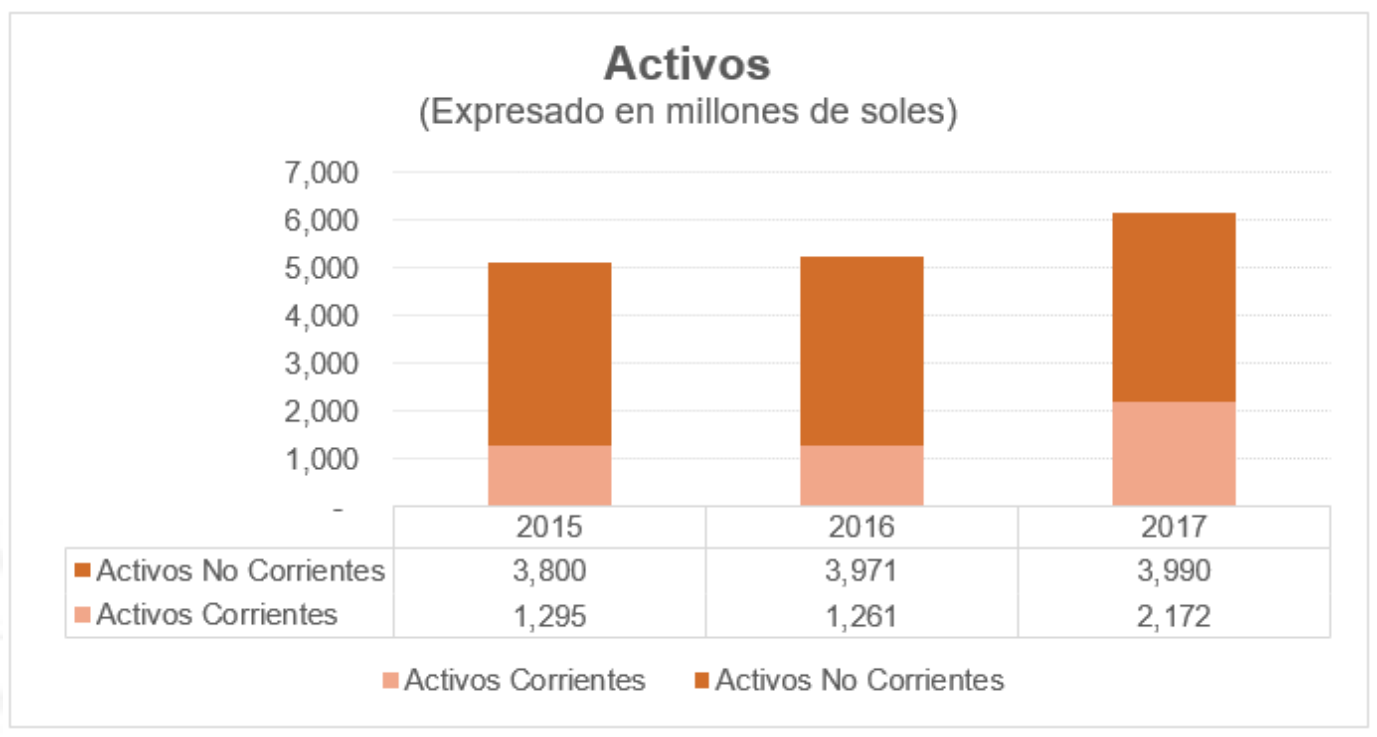

Elaboración propia

Al 31 de diciembre de 2016, el total de activos se incrementó en S/137.0 millones (2.7\%) con respecto al saldo al 31 de diciembre de 2015, principalmente por el incremento de S/171.1 millones en activos no corrientes y la disminución de S/34.1 millones en activos corrientes (Ver anexo 1).

La variación en activos no corrientes se explica principalmente por el incremento de las cuentas por cobrar a entidades relacionadas y en las inversiones a subsidiarias, contrarrestado con la disminución en el rubro de propiedades, planta y equipo. Mientras que la variación en activos corrientes se explica principalmente por la disminución en los inventarios y el activo por impuesto a las ganancias, contrarrestado con el incremento en el efectivo y equivalente de efectivo, las cuentas por cobrar a entidades relacionadas y los activos disponibles para la venta.

Al 31 de diciembre de 2017, el total de activos se incrementó en S/930.8 millones (17.8\%) con respecto al año anterior, principalmente por el incremento de S/911.7 en activos corrientes y el incremento de S/19.1 millones en activos no corrientes (Ver anexo 2). 
La variación en activos corrientes se explica principalmente por el incremento de efectivo y equivalente de efectivo, otros activos financieros, inventarios, anticipos a proveedores y cuentas por cobrar comerciales terceros, contrarrestando con la disminución en los activos disponibles para la venta. Por otro lado, la variación en activos no corrientes se explica principalmente por el incremento en el valor de la inversión en subsidiarias por efecto del valor de participación patrimonial y el incremento de los activos intangibles, contrarrestado por la disminución en cuentas por cobrar a partes relacionadas y en propiedades, planta y equipo.

\section{Efectivo y equivalente de efectivo}

La variación del rubro efectivo y equivalente de efectivo se muestra en el siguiente recuadro:

Figura 4.8

Variación de efectivo y equivalente de efectivo 2017 - 2015

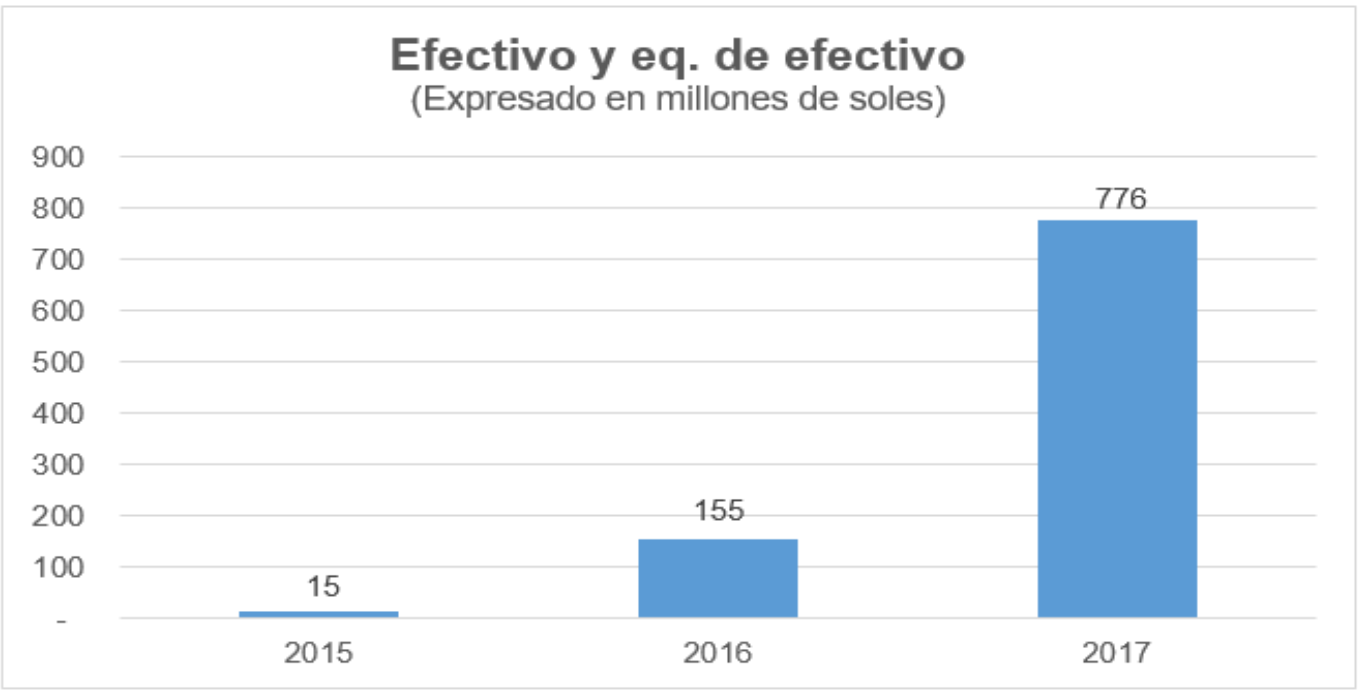

Elaboración propia

El efectivo y equivalentes de efectivo se incrementó de S/15.2 millones a diciembre de 2015 a S/155.1 millones a diciembre 2016. En el 2017 se incrementó a S/776.2 millones a diciembre de 2017. Esto se interpreta en una mayor liquidez explicado por mejoras en la gestión de capital de trabajo y mejoras en la utilidad operativa. 
Esta mejora se puede observar con el cálculo del ratio Liquidez-caja, el cual es un indicador que mide la liquidez ante las obligaciones de corto plazo con el efectivo que dispone y depósitos bancarios. Se muestra a continuación:

Tabla 4.3

Índice financiero: Rotación Liquidez - Caja

\begin{tabular}{|c|r|r|r|}
\hline Ratio & \multicolumn{1}{|c|}{$\mathbf{2 0 1 5}$} & \multicolumn{1}{c|}{$\mathbf{2 0 1 6}$} & \multicolumn{1}{c|}{$\mathbf{2 0 1 7}$} \\
\hline Liquidez-caja (tesorería) & 0.01 & 0.12 & 0.34 \\
\hline
\end{tabular}

Elaboración propia

Asimismo, Equilibrium Clasificadora de Riesgo S.A. (2018) señala: "Viene desplegando diversos esfuerzos por seguir optimizando la gestión de sus recursos y minimizar cualquier impacto. Por su parte, la posición de liquidez del negocio le ha permitido consolidarse en el máximo histórico de capital de trabajo superavitario".

\section{Cuentas por cobrar comerciales}

Figura 4.9

Variación de las cuentas por cobrar comerciales 2017 - 2015

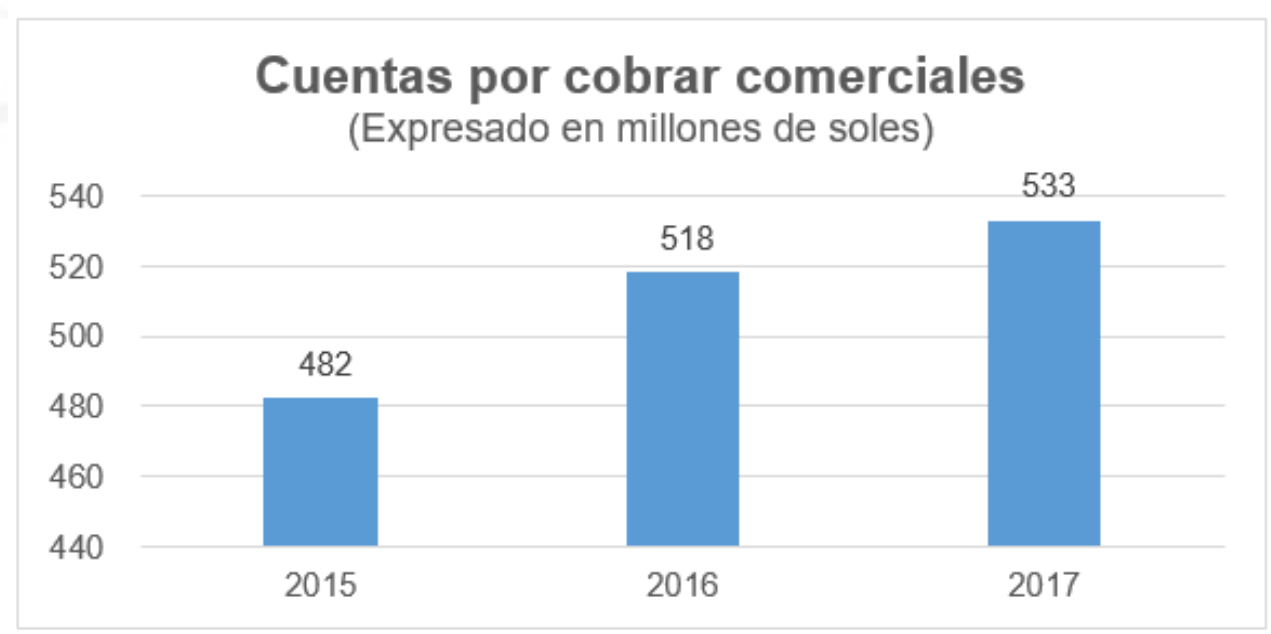

Fuente: Elaboración propia

Las cuentas por cobrar comerciales se incrementaron de S/482.2 millones a diciembre de 2015 a S/518.2 millones a diciembre de 2016. Igualmente, en el año 2017 se incrementó a S/533.0 millones.

El ratio de rotación de cuentas por cobrar nos muestra lo siguiente: 
Tabla 4.4 Índice financiero: Rotación de cuentas por cobrar

\begin{tabular}{|l|c|c|c|}
\hline \multicolumn{1}{|c|}{ Ratios } & $\mathbf{2 0 1 5}$ & $\mathbf{2 0 1 6}$ & $\mathbf{2 0 1 7}$ \\
\hline Rotación de cuentas por cobrar & 8.10 & 8.08 & 8.05 \\
\hline Días de venta por cuentas por cobrar & 44.44 & 44.56 & 44.73 \\
\hline
\end{tabular}

Elaboración propia

La cobranza se realizó en un promedio de 44.56 días durante el 2016 versus 44.44 días durante el 2015. En el año 2017, se realizó en un promedio de 44.73 días por lo que hubo un ligero incremento en $0.4 \%$ con respecto al año anterior. Esto quiere decir que las cobranzas están mejorando a pesar de que las cuentas por cobrar aumentan.

\section{Inventarios}

La variación del rubro de inventarios se muestra a continuación:

Figura 4.10

Variación de los inventarios 2017 - 2015

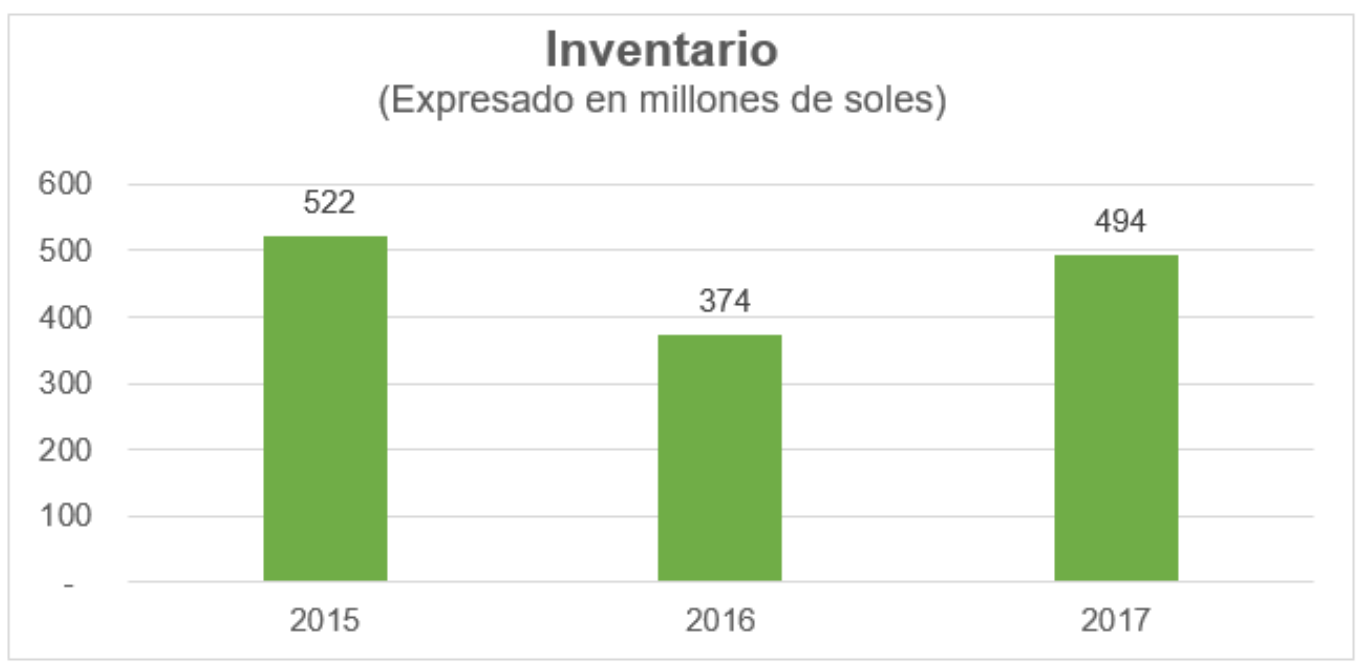

Elaboración propia

Los inventarios disminuyeron de S/522.4 millones a diciembre 2015 a S/374.3 millones a diciembre 2016. Sin embargo, los inventarios se incrementaron a S/494.2 millones a diciembre de 2017, explicado por una mayor estimación de volumen de ventas.

El ratio de rotación de cuentas por cobrar nos muestra lo siguiente: 
Tabla 4.5

Índice financiero: Rotación de inventarios

\begin{tabular}{|l|c|c|c|}
\hline \multicolumn{1}{|c|}{ Ratios } & $\mathbf{2 0 1 5}$ & $\mathbf{2 0 1 6}$ & $\mathbf{2 0 1 7}$ \\
\hline Rotación de inventarios & 5.49 & 6.21 & 6.50 \\
\hline Días de venta por inventario & 65.59 & 57.98 & 55.40 \\
\hline
\end{tabular}

Fuente: Elaboración propia

En el año 2017, disminuyó de 57.9 días a 55.4 días. Esto quiere decir que no se tiene muchos días de inventario por lo cual es un buen indicador para evaluar la calidad de la gestión del abastecimiento de existencias y stocks.

\section{Propiedades, planta y equipo}

El rubro de propiedades, planta y equipo aumentó en un neto de S/73.4 millones, de S/1,201.6 millones a diciembre 2015 a S/1,128.2 millones a diciembre 2016. En el año 2017, disminuyo a S/ 1098.1 millones.

Figura 4.11

Variación de propiedades, planta y equipo 2017 - 2015

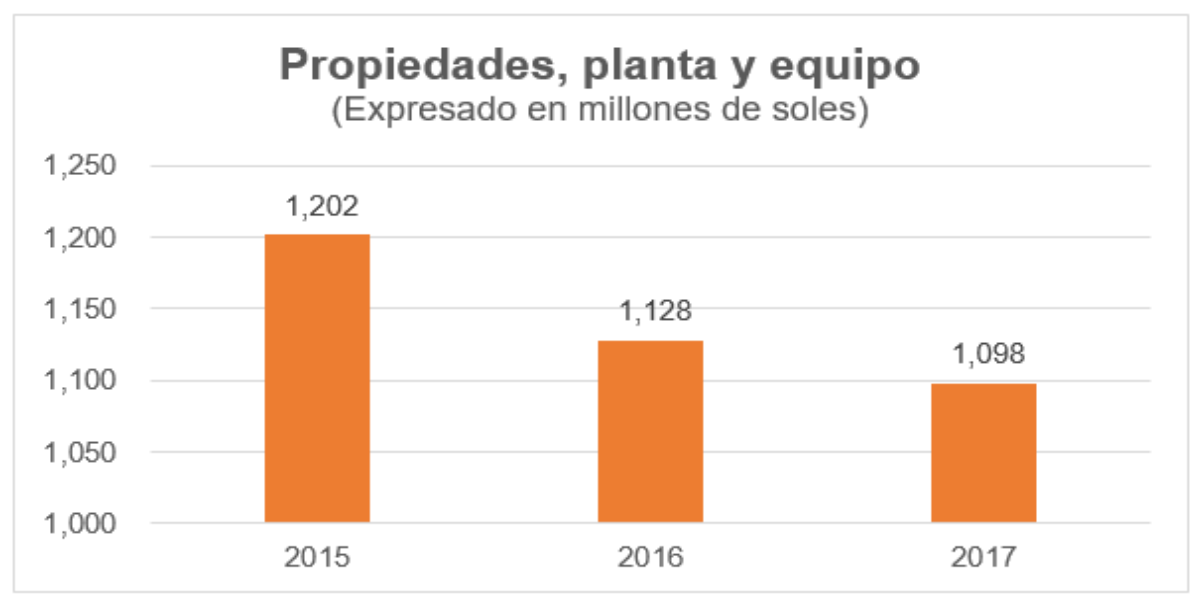

Elaboración propia

El incremento en el año 2017 se debe a que ocurrió una adquisición de envasadora para la planta Galletera Callao y equipos para la adecuación de la planta de desodorización.

EY Perú (2017), menciona lo siguiente: "Durante el ejercicio 2016, la principal transferencia recibida del rubro "Propiedades, planta y equipo, neto" corresponde al terreno y edificios de la ex planta Breña ubicada en Jr. Chamaya, Breña por un costo neto de $\mathrm{S} / 10,142,000 ”($ p. 49) 


\section{Activos intangibles}

Figura 4.12

Variación de activos intangibles 2017 - 2015

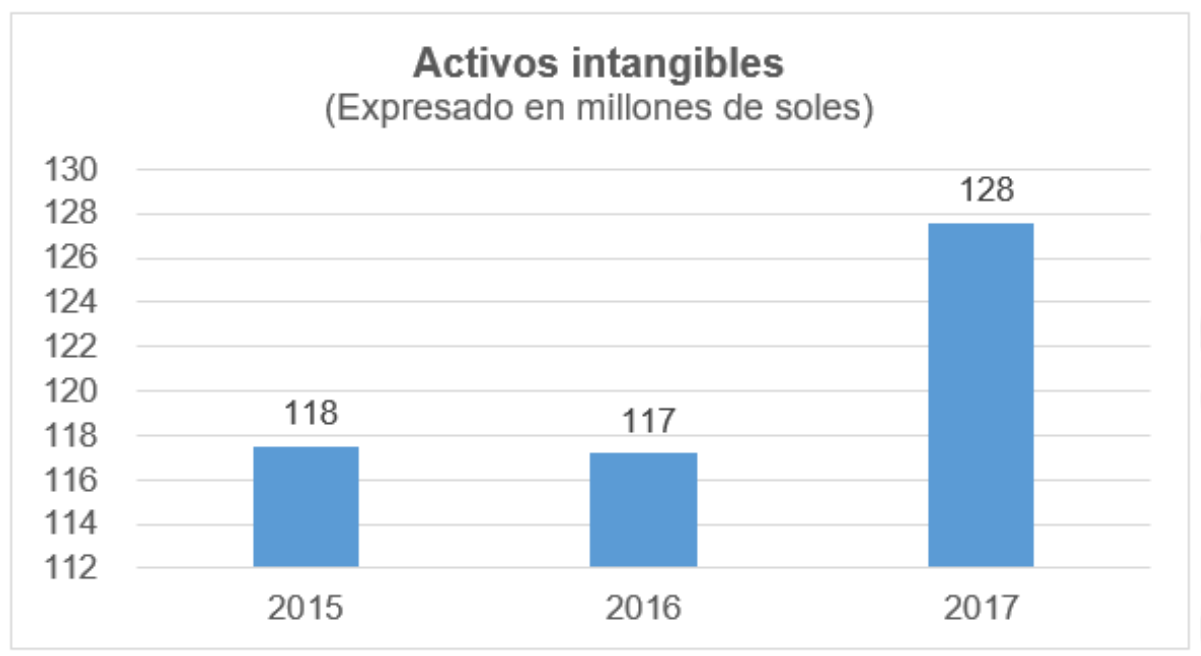

Fuente: Elaboración propia

Entre los años 2015 y 2016 no hubo una variación significativa. Sin embargo, los activos intangibles se incrementaron en un neto de S/10.4 millones, de S/117.2 millones a diciembre de 2016 a S/127.6 millones a diciembre de 2017, explicado por la mayor inversión en licencias y desarrollo de módulos en el ERP/SAP.

\section{Pasivos y Patrimonio}

Figura 4.13

Variación de pasivos 2017 - 2015

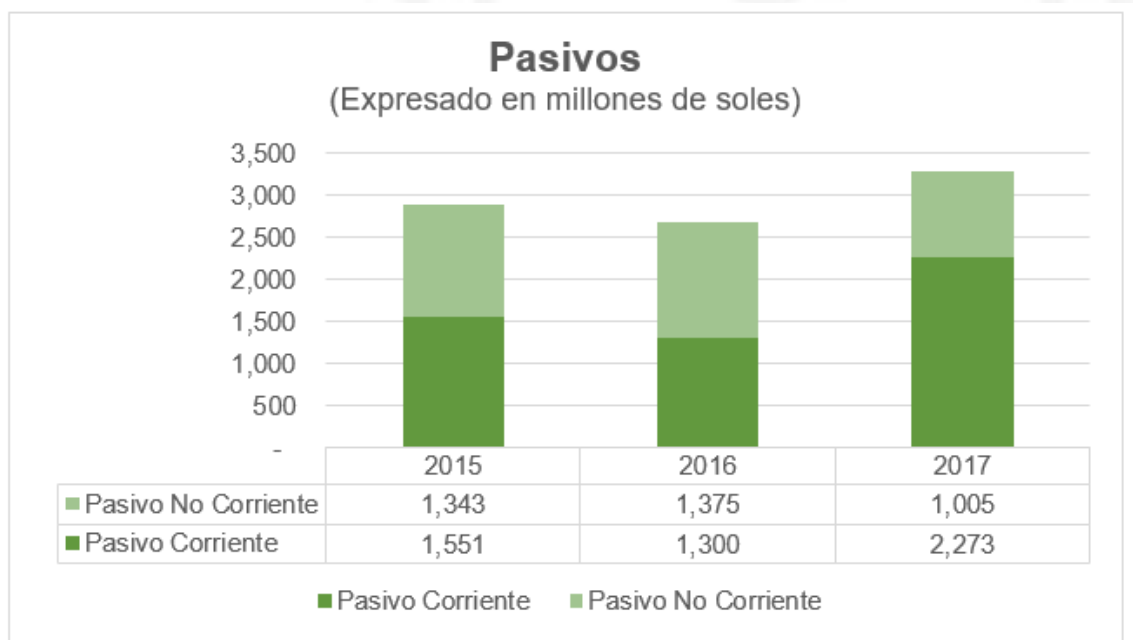

Elaboración propia 
Al 31 de diciembre de 2016, el total de pasivos fue de S/ 2,675.6 millones el cual disminuyó en S/218.9 millones (-7.6\%) con respecto al saldo al 31 de diciembre de 2015. Esta variación se explica principalmente por la reducción en otros pasivos financieros corrientes, cuentas por pagar comerciales, contrarrestado por el incremento en la provisión de beneficios sociales, otros pasivos financieros no corrientes y el pasivo por impuesto diferido.

Los pasivos corrientes disminuyeron en S/251.0 millones, debido principalmente a la reducción de S/207.7 millones de otros pasivos financieros corriente y a la disminución de las cuentas por pagar comerciales en S/93.7 millones, compensados con el incremento de la provisión de beneficios sociales en S/27.4 millones y el pasivo por impuesto a las ganancias en $\mathrm{S} / 13.5$ millones.

Los pasivos no corrientes se incrementaron en S/32.1 millones, relacionado principalmente con el incremento de S/23.1 millones de deuda financiera no corriente.

Al 31 de diciembre de 2017, el total de pasivos se incrementó en S/603.2 millones (22.5\%) llegando a S/. 3,278.8. Esta variación se explica principalmente por el incremento de otros pasivos financieros corrientes, cuentas por pagar comerciales, pasivo por impuesto a las ganancias, contrarrestado por la disminución de otros pasivos financieros no corrientes.

Los pasivos corrientes del 2017 se incrementaron en S/973.0 millones, debido principalmente a los incrementos de S/732.4 millones de otros pasivos financieros corriente, explicados por financiamientos obtenidos de entidades financieras; cuentas por pagar comerciales en S/188.7 millones, pasivo por impuesto a las ganancias por S/21.0 millones.

Adicionalmente, al 31 de diciembre de 2017 y de 2016, los préstamos bancarios fueron utilizados principalmente para capital de trabajo. Ello explica el resultado de éste; mostrando que el activo corriente es 0.96 veces menor al pasivo corriente al año 2017.

Los pasivos no corrientes disminuyeron en S/369.8 millones, relacionado principalmente con la disminución de S/348.0 millones de otros pasivos financieros no corriente.

En el siguiente recuadro se muestra el siguiente índice financiero: 
Tabla 4.6

Índice financiero: Endeudamiento patrimonial

\begin{tabular}{|l|c|c|c|}
\hline & $\mathbf{2 0 1 5}$ & $\mathbf{2 0 1 6}$ & $\mathbf{2 0 1 7}$ \\
\hline Endeudamiento Patrimonial & 1.32 & 1.05 & 1.14 \\
\hline
\end{tabular}

Fuente: Elaboración propia

Alicorp financia su capital sobre la base del ratio de apalancamiento. Este ratio se calcula midiendo la intensidad de toda la deuda de la empresa en relación a su patrimonio.

El apalancamiento patrimonio se incrementa ligeramente de 1.05 en el 2016 a 1.14 veces en el 2017 debido al aumento en las cuentas por pagar. Lo cual nos muestra que no registra una buena capacidad de pago frente a sus deudas financieras, lo cual no contribuye con la buena toma de decisiones de los acreedores.

\section{Pasivos Financieros}

Figura 4.14

Evolución de los pasivos financieros 2017 - 2015

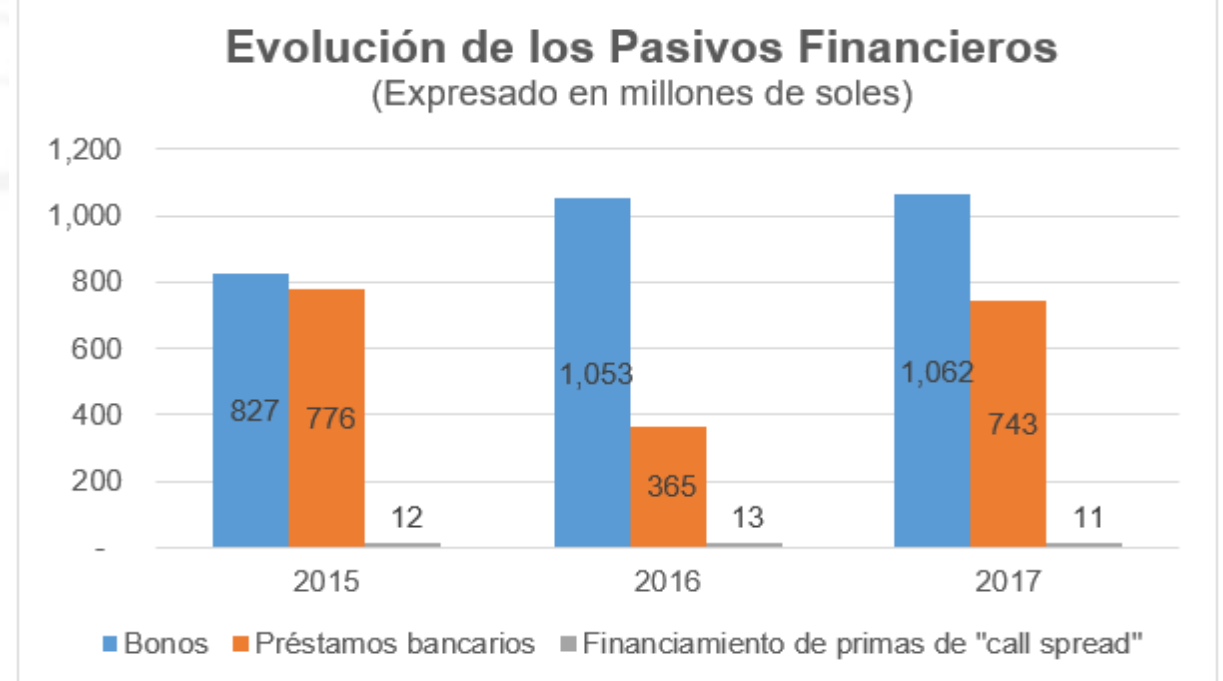

Elaboración propia

La deuda financiera se compone de bonos corporativos emitidos a nivel local, seguido de préstamos bancarios y financiamiento de primas de "call spread".

A su vez, ésta podemos dividirla en porción corriente y no corriente:

En el año 2016, la deuda financiera corriente totalizó en S/ 142.73 millones representando el $10.0 \%$ del total de la deuda financiera. Esto se debe a que la gerencia de 
Alicorp aprobó realizar una nueva compra privada por un monto total de US\$400,000 generando una ganancia de S/27,000. (EY Peru, 2017)

La deuda financiera corriente totalizo S/ 877.03 millones a diciembre de 2017. La parte no corriente, totalizó S/939.57 millones a diciembre de 2017, representando el 51.5\% del total de la deuda financiera. Del cual, los bonos componen casi la totalidad de la cuenta (S/ 930.03 millones de soles).

Según EY Perú (2017), al 31 de diciembre de 2017 y de 2016, los préstamos bancarios fueron utilizados principalmente para capital de trabajo.

La variación del patrimonio entre los años 2015 y 2017 es la siguiente:

Figura 4.15

Variación del patrimonio 2017 - 2015

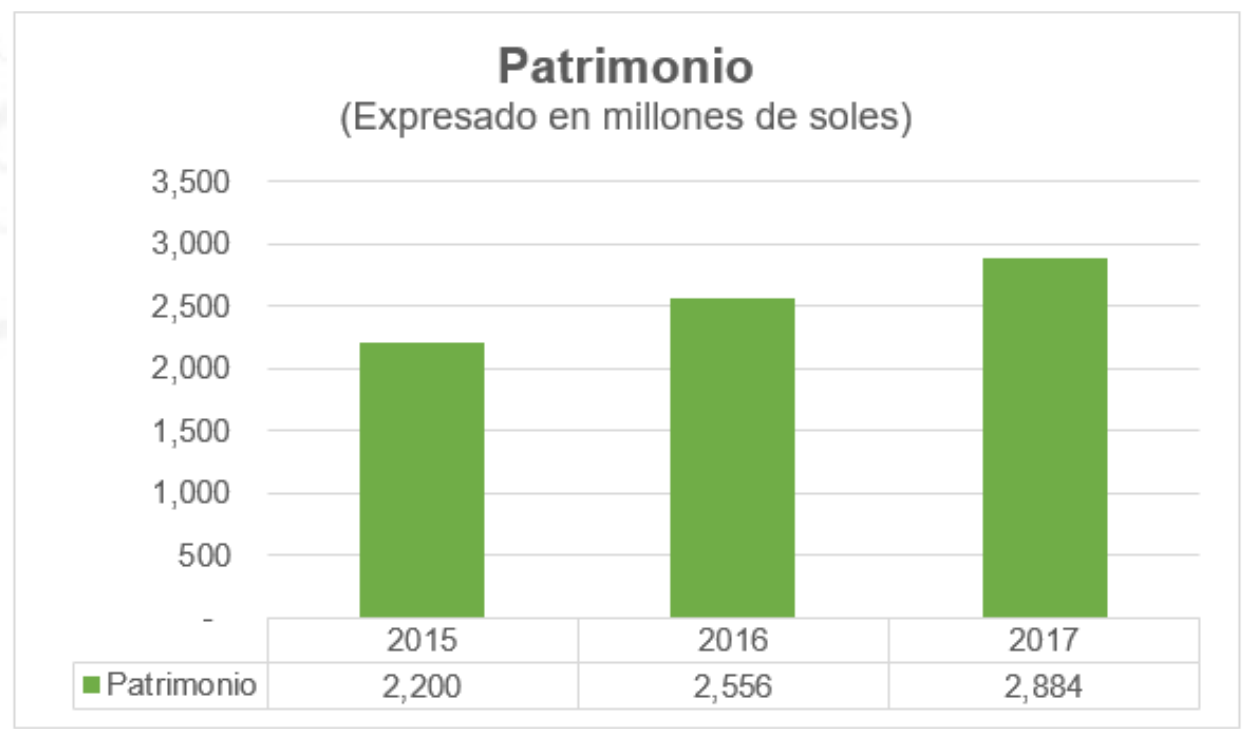

Elaboración propia

El patrimonio de Alicorp aumentó de S/2,200.2 millones a diciembre 2015 a S/2,556.1 millones a diciembre 2016 (incremento de 16.2\%), debido principalmente a la utilidad del periodo de S/302.5 millones, y a la ganancia en el reconocimiento del valor patrimonial en subsidiarias y asociadas por S/101.9 millones, compensados por la distribución de dividendos por S/46.1 millones.

En el 2017 el patrimonio nuevamente se incrementó a S/2,883.7 millones a diciembre de 2017, debido principalmente a la utilidad del periodo de S/453.1 millones, disminuido por 
la distribución de dividendos por S/119.6 millones y otras reservas de patrimonio por S/6.7 millones.

Equilibrium (2017) indica que:

Un punto de consideración es que la Compañía tiene una política de reparto de dividendos de por lo menos el $10 \%$ de las utilidades de cada ejercicio tras la aprobación de la Junta Obligatoria Anual de Accionistas; no obstante, históricamente el ratio promedio de los últimos cuatro ejercicios muestran una tasa cercana al $32.5 \%$. En tal sentido es importante indicar que en el ejercicio 2015 no se repartieron dividendos con la finalidad de fortalecer el negocio; en tanto que en el ejercicio 2016 y primer semestre de 2017 se autorizó el reparto de dividendos por S/ 46.1 millones y S/ 119.6 millones, respectivamente. (p. 6).

Tabla 4.7

Índice financiero: Rentabilidad sobre patrimonio

\begin{tabular}{|l|l|l|l|}
\hline \multicolumn{1}{|c|}{ Ratio } & $\mathbf{2 0 1 5}$ & $\mathbf{2 0 1 6}$ & $\mathbf{2 0 1 7}$ \\
\hline $\begin{array}{l}\text { Rentabilidad sobre } \\
\text { patrimonio }\end{array}$ & 0.07 & 0.12 & 0.16 \\
\hline
\end{tabular}

Elaboración propia

Desde el año 2015 el ROE ha ido incrementándose, siendo en el año 2016 alcanzó el 12\%. Y al 31 de diciembre de 2017, el ROE alcanzo el 16.7\%. Esto quiere decir que Alicorp S.A.A. tiene una mejor rentabilidad en función a los recursos propios que emplea para financiarse.

\subsubsection{Interpretación de la NIIF 15 en Alicorp S.A.A.}

Los ingresos de Alicorp S.A.A. corresponden principalmente a la venta de bienes de consumo masivo por lo que la compañía realiza la entrega del bien a los clientes en un momento determinado. Existen otros ingresos, que corresponden a servicios de asistencia técnica que son ofrecidos a los clientes en la cual la transferencia del beneficio es a lo largo de un periodo, mientras que las regalías son reconocidas en un momento determinado cuando se les cobra a sus distribuidores. En todos los casos, se firman contratos, que integran bienes y/o servicios. 
Los ingresos constituyen el centro de las preocupaciones de todo negocio, y Alicorp S.A.A. no es ajeno a ello. La compañía debe revisar y evaluar estos temas con el debido apremio puesto que los cambios conllevan mucho tiempo para lograr su implementación.

Alicorp S.A.A. tiene previsto aplicar la nueva norma en la fecha efectiva requerida utilizando el método de retroactivo total, por lo que durante el año 2017 se ha efectuado una evaluación de los impactos de la NIIF 15, que fue culminada en el 2018.

El modelo de la NIIF 15 tiene 5 pasos y requiere de juicio profesional para su aplicación en la empresa:

\section{Paso 1: Identificación de los contratos con clientes}

Los criterios que se deben cumplir para que un contrato se encuentre dentro de los alcances de la NIIF 15 son:

- Aprobado por las partes

- Derechos de cada parte identificables

- Condiciones de pago identificables

- El contrato tiene fundamento comercial.

- Alta probabilidad de cobro de la contraprestación.

Alicorp tiene los siguientes tipos de contrato:

1) Acuerdos comerciales

2) Contratos específicos

3) Orden de pedido

Estos contratos cumplen con los criterios establecidos en la norma con excepción de los acuerdos comerciales puesto que no se establecen las condiciones de pago ya que dichas condiciones se establecen por cada pedido especifico. Por lo tanto, se puede concluir que en este paso se identificaron diferencias. 
Tabla 4.8

Criterio de contrato identificados en Alicorp S.A.A.

\begin{tabular}{|c|c|c|c|c|c|c|}
\hline \multirow[b]{2}{*}{$\begin{array}{l}\text { Tipo de } \\
\text { Contrato }\end{array}$} & \multicolumn{5}{|c|}{ Relación de criterios identificados } & \multirow[b]{2}{*}{$\begin{array}{c}\text { ¿Se } \\
\text { identifica } \\
\text { un } \\
\text { contrato? }\end{array}$} \\
\hline & $\begin{array}{c}\text { Aprobado } \\
\text { por las partes }\end{array}$ & $\begin{array}{c}\text { Derechos } \\
\text { identificables }\end{array}$ & $\begin{array}{c}\text { Condiciones } \\
\text { de pago } \\
\text { identificables }\end{array}$ & $\begin{array}{l}\text { Fundament } \\
\text { o comercial }\end{array}$ & $\begin{array}{c}\text { Alta } \\
\text { probabilidad } \\
\text { de cobro de la } \\
\text { contraprestaci } \\
\text { ón } \\
\end{array}$ & \\
\hline $\begin{array}{l}(1) \\
\text { Acuerdos } \\
\text { comerciales }\end{array}$ & $\checkmark$ & $\checkmark$ & $\mathrm{X}$ & $\checkmark$ & $\checkmark$ & NO \\
\hline \begin{tabular}{|l|} 
(2) \\
Contrato \\
específicos
\end{tabular} & $\checkmark$ & $\checkmark$ & $\checkmark$ & $\checkmark$ & $\checkmark$ & Sí \\
\hline $\begin{array}{l}\text { (3) } \\
\text { Orden de } \\
\text { pedido }\end{array}$ & $\checkmark$ & $\checkmark$ & $\checkmark$ & $\checkmark$ & $\checkmark$ & Sí \\
\hline
\end{tabular}

Fuente: Alicorp (2018).

Paso 2: Identificación de las obligaciones de desempeño

En Alicorp, se han identificado las siguientes obligaciones:

Tabla 4.9

Obligaciones de desempeño de la Compañía

\begin{tabular}{|c|c|c|c|}
\hline Bienes y servicios comprometidos & $\begin{array}{l}\text { ¿Es distinta para el } \\
\text { cliente? }\end{array}$ & $\begin{array}{l}\text { ¿Es distinta en el } \\
\text { contexto del } \\
\text { contrato? }\end{array}$ & $\begin{array}{c}\text { Combinación de } \\
\text { obligaciones }\end{array}$ \\
\hline Venta de bienes & Sí & NO & SÍ \\
\hline Transporte $^{1}$ & SÍ & NO & SÍ \\
\hline Regalías por volumen de ventas (DEX) & SÍ & SÍ & NO \\
\hline Fidelización de clientes & Sí & SÍ & $\mathrm{NO}$ \\
\hline Maquila de productos & Sí & Sí & $\mathrm{NO}$ \\
\hline Bienes en comodato & Sí & Sí & NO \\
\hline Exhibidores & Sí & Sí & $\mathrm{NO}$ \\
\hline Asesoría Técnica ${ }^{2}$ & Sí & SÍ & NO \\
\hline
\end{tabular}

Fuente: Alicorp (2018).

${ }^{1}$ Cabe mencionar que las ventas y transporte representan como una sola obligación de desempeño.

${ }^{2}$ Esta obligación de desempeño es parte solo de la línea de negocio B2B. 
La norma establece determinar las obligaciones de desempeño identificando dos criterios que deben cumplirse para poder llamarse como tal:

a) Un bien o servicio distinto o no para el cliente

Cuando el bien o servicio es capaz de ser distinto para el cliente:

- $\quad$ Este puede beneficiarse del bien o servicio individual por sí mismo

- Utilizar el bien o servicio en combinación con otros recursos disponibles.

Alicorp S.A.A. tiene negocios que brindan servicios específicos adicionales a las actividades las cuales brindan un beneficio individual por sí mismo, pero no son vendidos por separado. Este se da en el caso de las actividades de venta y transporte de mercaderías puesto que genera que exista un bien y un servicio y en el que cada una de ellas puede ser realizada de manera independiente.

b) Un bien o servicio distinto o no en el contexto del contrato

Para que se considere como uno:

- No depende en gran medida de,

- No está muy interrelacionado con,

- No modifica o personaliza sustancialmente otros bienes o servicios comprometidos en el contrato.

La NIIF 15 no impide que una entidad contabilice los bienes o servicios como si fueran una única obligación de desempeño, siempre y cuando el resultado sea el mismo que contabilizarlos como obligaciones de desempeño independientes.

En este punto, Alicorp S.A.A. evalúa si dos o más obligaciones de desempeño comprometidas son altamente interdependientes o interrelacionados en el contexto de los contratos.

Las obligaciones de desempeño identificadas corresponden a una serie de servicios distintos por sí mismo, pero que en el contexto del contrato son sustancialmente los mismos por tener el mismo patrón de transferencia.

Siguiendo con el ejemplo de la venta y transporte del bien, este se realiza cuando el bien se entrega en el lugar acordado con el cliente por lo que se reconoce como una única obligación de desempeño ya que la aceptación del cliente se da una 
vez que se entreguen estos bienes. Por otro lado, las regalías por volumen de ventas (DEX), fidelización de clientes, maquila de productos, bienes en comodato, exhibidores se consideran como obligaciones de desempeño separadas.

\section{Paso 3: Determinar el precio de la transacción}

La norma indica que se considerara los términos del contrato y sus prácticas de negocio para determinar el término de la transacción.

Alicorp S.A.A. determina el precio en base a los descuentos que mantienen por canal y por oficina, entre otros, tal como se detalla a continuación:

Precio Base

(-) Ajuste al precio base por oficina y canal

(-) Descuentos:

- Segmentación

- Comercial

- Promociones

- Logística

- Financiero

(-) Ajuste por devoluciones

Precio de venta neto

Las compañías considerarán la siguiente fórmula para el cálculo del precio de transacción:

$\begin{aligned} & \text { Precio de la } \\ & \text { transacción }\end{aligned}=\begin{aligned} & \text { Contraprestación } \\ & \text { Fija }\end{aligned}-\begin{aligned} & \text { Contraprestación } \\ & \text { Variable }\end{aligned}-\begin{aligned} & \text { Contraprestación } \\ & \text { a pagar al cliente }\end{aligned}$

Donde:

- Contraprestación Fija: Es el precio base

- Contraprestación Variable: Corresponde a los descuentos comerciales, descuento por linealidad, bonificaciones regulares, devoluciones

- Contraprestación a pagar al cliente: Se encuentran establecidas como créditos o pagos en efectivo. 


\section{Paso 4: Asignar el precio de la transacción a las obligaciones de desempeño}

La norma indica que se debe asignar el precio de la transacción y distribuirlo a cada obligación de desempeño, por un importe que represente la parte de la contraprestación a la cual la entidad espera tener derecho a cambio de transferir los bienes o servicios brindados al cliente.

Actualmente, en Alicorp S.A.A. se reconocen los ingresos solo por la venta de productos y no se consideran otras obligaciones de desempeño. En el caso de los DEX, las regalías que la compañía reconoce, estas se encuentran dentro de "otros ingresos".

En el caso de bienes y transporte, estos se consideran como una sola obligación de desempeño y se debe hallar el precio de venta independientemente de la obligación de desempeño. El precio de los bienes se determina a través de los precios directamente observables en el mercado del bien y en el transporte, se determinaría a través del método del costo más margen.

Paso 5: Reconocer los ingresos cuando cada obligación de desempeño se haya alcanzado

El ingreso se reconoce cuando se satisface la obligación de desempeño mediante la transferencia del control al cliente de un bien o servicio.

Alicorp S.A.A. no registra el ingreso por el importe asignado a cada obligación de desempeño comprometida. Por lo cual, debería reconocer el ingreso correspondiente a cada obligación cuando sea realizada. En el caso de venta y transporte, el cumplimiento de ambas se realiza en el momento de la entrega del bien en el lugar acordado con el cliente. Es en este momento en el que se realiza la transferencia del control del bien.

En el caso de los DEX, el ingreso que obtiene Alicorp S.A.A. correspondiente a las regalías de acuerdo al contrato, son relacionadas a la venta que genera con estos, por lo que serán reconocidas en el momento en que tenga lugar la venta.

En resumen, todas las obligaciones de desempeño se reconocerán en un momento en el tiempo; excepto para los bienes en comodato puesto que los bienes son controlados por el 
cliente mientras se encuentre en el lugar entregado por Alicorp S.A.A. y el uso del mismo es continuo.

\subsection{Presentación y discusión de resultados}

\subsubsection{Impacto de la NIIF 15 en el Estado de Resultados de Alicorp S.A.A.}

Se presenta el Estado de Resultados proyectado del año 2018 y del 2017 de la empresa Alicorp S.A.A con la implementación de la NIIF 15 del 2018 y reclasificación del año 2017).

Tabla 4.10

Estado de Resultados proyectado 2018 y 2017

\section{ALICORP S.A.A. ESTADO DE RESULTADOS}

Por los años proyectados al 31 de diciembre de 2018 y 2017

(En miles de soles)

Costo de ventas

Utilida Bruta

Gastos de ventas y distribución

Gastos administrativos

Resultados de operaciones con derivados de materias primas

Otros ingresos y gastos, neto

Utilidad Operativa

Ingresos financieros

Gastos financieros

Diferencia de cambio neto

Participación en los resultados netos de subsidiarias y asociadas

\section{Utilidad neta}

Nota

(A)

(B)

2018

(S/ 000)

2017

(S/ 000)

$4,230,270$

$4,368,217$

$(2,822,091)$

$1,408,179$

$(\mathrm{A}, \mathrm{B})$

$(434,084)$

$(360,049)$

$(645,171)$

$(293,875)$

2,319

$(8,290)$

22,059

485,411

18,959

$(\mathrm{A}, \mathrm{B})$

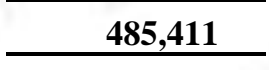

$\mathbf{4 7 9 , 8 0 2}$

30,129
$(127,279)$
$(3,638)$

43,460

$(99,074)$

$(7,783)$

100,496

154,356

\begin{tabular}{ll}
485,119 & 570,761 \\
\hline \hline
\end{tabular}

Fuente: Elaboración propia 
A continuación, se realizará el análisis del impacto de la NIIF 15 de la empresa Alicorp S.A.A. en el Estados de Resultados de 2018.

\section{A) Análisis de las Ventas Netas}

Tabla 4.11

Ventas proyectadas en el 2018

Por el año 2018

Impacto en $S / 000$

Ventas netas antes de aplicación NIIF 15

Regalías relacionadas $4,537,354$

Regalías DEX

583

Recupero de acarreos

Ingreso por acarreos

160

Regalías relacionadas NIIF 15

64

Comisiones DEX

168,488

Comisiones Relacionadas

Comisiones DEX SubProd SC

Ventas netas Total

$(1,757)$

$4,705,194$

Fuente: Elaboración propia

El área de impacto en el estado de resultado es a nivel de Utilidad Bruta. Esto se debe a que varios de los conceptos que se encontraron dentro del rubro "otros ingresos y gastos" se han trasladado a la cuenta del rubro de Ventas Netas como en el caso de los siguientes elementos:

- Las regalías relacionadas y las regalías DEX vienen de ingresos diversos y a partir del año 2018 (en el que entra a vigencia) se consideraran como parte de los ingresos por ventas.

- $\quad$ Las comisiones DEX y las relacionadas son cuentas que se muestran dentro del ingreso de ventas. Antes se consideraban como parte del gasto lo cual se reclasifica como un ajuste de precio que afecta este rubro. 
Esto trae como consecuencia que las ventas netas se disminuyen. En base al supuesto, ésta disminuiría en $3.26 \%$ en el 2018 con respecto al año anterior. Este impacto no es significativo en los resultados, debido a que se trata de obligaciones contractuales.

\section{B) Análisis del Costo de Ventas}

Tabla 4.12

Costo de ventas proyectados en el 2018

\section{Por el año 2018 \\ Impacto en $\mathrm{S} / 000$}

Costo de venta antes de aplicación NIIF 15

$(2,996,132)$

Transferencias gratuitas NIIF 15

Asesoría técnica NIIF 15

Asesoría técnica Depreciación NIIF 15

Acarreos

Regalías Relacionadas NIIF 15

$(6,067)$

Costo de ventas Total

$(3,113,051)$

Fuente: Elaboración propia

Al igual que en los ingresos, el costo de ventas se incrementaría en un 10,3\% en el año 2018 debido a la reclasificación de las siguientes cuentas:

- Las transferencias gratuitas de los productos de Alicorp S.A.A. que se realizan con los clientes formaban parte de gastos diversos. Pasará a ser parte del costo de ventas puesto que le otorgan mayor cantidad de bienes a los clientes

- Las asesorías técnicas corresponden a capacitaciones en las operaciones de panificación para garantizar un buen manejo del proceso y horneado del pan. Estas formaban parte del gasto de ventas.

- El acarreo es el costo del transporte era parte del gasto "Acarreos".

- Las regalías que se efectúan con las relacionadas estaban dentro del gasto "Comisiones". 
La adopción de la NIIF 15 trae como consecuencia la reclasificación de los "Gastos de ventas y distribución" al rubro de "Costo de Ventas". Esto se verá reflejado de la misma manera al momento de presentar los ingresos y gastos.

Por otro lado, la compañía deberá incrementar la divulgación de los juicios significativos dentro del Estado de Resultados ya sea para la determinación de precios y la transacción a las obligaciones de desempeño identificadas. Además de la necesidad de explicar en las políticas contables de los Estados financieros. Por ejemplo: Saber porque se ha determinado un ingreso por ventas y el transporte de los productos hasta los almacenes del cliente

La desagregación de las obligaciones de desempeño identificadas, trae como consecuencia cambios en los elementos del Estado de Resultados e indicadores financieros por lo que deben evaluarse los más significativos para la toma de decisiones.

La información que presenta Alicorp debería ayudar al mejor entendimiento de los ingresos por contratos como, por ejemplo: tipo de bien, canales y/o momento de las transferencias de control.

\subsubsection{Proyección de los Estados Financieros de Alicorp S.A.A. del 2018 al 2020}

Para elaborar la proyección de Alicorp S.A.A. del 2018 al 2020 se tomaron los rubros de mayor relevancia: (Ver anexo 4)

\section{Estado de Resultados}

- En el rubro de Ingresos se tomó en consideración:

- PBI general: $4 \%$

- $\quad$ PBI Sectorial (Manufactura No primaria): $3.8 \%$

- A partir del año 2018 Alicorp S.A.A. viene creciendo aproximadamente de $3 \%$ Para realizar la proyección se utilizará la tasa promedio: $3.6 \%$

- El margen bruto de Alicorp S.A.A. se toma como referencia el año 2018 que tiene como porcentaje promedio el 30\% por la aplicación de la NIIF 15. Los ejercicios anteriores mostraban un promedio de $34 \%$.

- El gasto de venta se toma como referencia el año 2018 que tiene como porcentaje 
promedio $10 \%$ por la aplicación de la NIIF 15. Los ejercicios anteriores mostraban un promedio de $15 \%$.

\section{Estado de Situación Financiera}

- En el rubro de cuentas por cobrar comerciales se ha incrementado en un $4 \%$ como consecuencia del incremento en las ventas netas.

- Las cuentas por cobrar relacionadas se incrementaron en 30\% producto de las ventas exportación Bolivia a las compañías relacionadas Fino y ADM Sao (adquisiciones realizadas en el segundo semestre del año 2018).

- Los inventarios se incrementaron en un $10 \%$ por una oportunidad de compra en materia primas commodities (granos de trigo). Hay una tendencia al alza en los próximos meses.

Para la proyección de los años 2019 y 2020 se ha tomado como base la tendencia en la información histórica de los estados financieros de los años 2016, 2017 y 2018.

\subsubsection{Flujo de Caja Proyectado de Alicorp S.A.A. del 2018 al 2020}

De igual manera, para elaborar el flujo de caja proyectado de Alicorp S.A.A. del 2018 al 2020 se tomaron los rubros de mayor relevancia: (Ver anexo 5)

\section{Estado de Resultados}

- En el rubro de Ingresos se tomó en consideración:

- $\quad$ PBI general: $4 \%$

- $\quad$ PBI Sectorial (Manufactura No primaria): $3.8 \%$

- $\quad$ A partir del año 2018 Alicorp viene creciendo aproximadamente de $3 \%$ Para realizar la proyección se utilizará la tasa promedio: $3.6 \%$

- Para EBIT proyectado se consideró una tasa del 10\% (respecto a las ventas) como promedio de los años 2016 y 2017.

- Para la depreciación y amortización proyectada se consideró el 9.4\% (respecto a las ventas) como promedio de los años 2016 y 2017. 
- En el caso de la Inversión en Capital de Trabajo se tomó en consideración el capital de trabajo descontando los ingresos netos por venta y tomando un promedio de 2\% (respecto a las ventas) de los años 2016 y 2017.

- La tasa de impuesto a la renta se estableció en $29.5 \%$ 


\section{CAPÍTULO V: CONCLUSIONES Y RECOMENDACIONES}

\subsection{Conclusiones}

a) La situación financiera de Alicorp S.A.A. ha ido mejorando en el periodo de revisión 2015 - 2017. En el año 2017, su rentabilidad tiene un incremento en un 3.2\% a nivel de utilidad neta con respecto al año 2016. Esta variación positiva es reflejada por un mayor volumen de ventas en $2 \%$ e incremento de precio en 1\%. El EBITDA (utilidad antes de intereses, impuestos, depreciación y amortización) alcanzó los S/ 568 millones. Este crecimiento se explica por la mayor contribución del negocio Consumo Masivo Perú debido al ingreso de las nuevas categorías de conservas.

b) Con la adopción de la NIIF 15, Alicorp S.A.A. tiene la obligación de presentar la información en los estados financieros considerando la desagregación de los ingresos procedentes de actividades ordinarias, de acuerdo al tipo de bien, cliente, contrato, tiempo de transferencia de bienes, entre otros. Estos nuevos criterios de reconocimiento y medición son más detallados que las establecidas en las normas aplicadas en ejercicios anteriores. La adopción de esta nueva norma, está directamente ligada al reconocimiento de los ingresos y reclasificación de cuentas contables y el área de impacto en el estado de resultados integrales es a nivel de Utilidad Bruta.

c) La proyección financiera de Alicorp S.A.A. del 2018 al 2020 se realizó tomando en cuenta las variables que podrían influir al momento de estimar los rubros más significativos de la empresa y refleja la adopción de la NIIF 15 en el Estado de Resultados. Adicionalmente se ha considerado la situación macroeconómica y del sector al cual se vincula Alicorp S.A.A. 


\subsection{Recomendaciones}

a) Al manejar altos índices de liquidez le permite pagar las obligaciones con los proveedores y bancos en el corto plazo. Por este motivo es importante que Alicorp continúe aumentando sus ingresos para que de esta manera mejore los indicadores de eficiencia y rentabilidad

b) Es recomendable que Alicorp S.A.A. establezca una periodicidad del momento del reconocimiento de ingresos por cada obligación de desempeño que se identifique, tales como la venta y transporte de bienes, regalías por volúmenes de venta, exhibidores, entre otros.

c) Debido a que la adopción de la NIIF 15 está directamente ligada al reconocimiento de los ingresos, esta se ve afectada en la proyección del Estado de Resultados Integrales de la Compañía por lo que debería realizarse un seguimiento al impacto que existiría en base a las ventas netas, utilidad comercial, utilidad bruta, entre otros ratios que se verían involucrados. 


\section{REFERENCIAS}

Alicorp. (2018). Memoria Anual 2016. Lima.

Banco Central de Reserva del Peru. (2018, Setiembre). Reporte de Inflacion - Panorama actual y proyecciones macroeconomicas 2018-2019. Lima, Lima, Peru.

Deloitte. (2017). Implementacion de la NIIF 15 Ingresos ordinarios derivados de contratos con clientes. 3. Retrieved from https://www2.deloitte.com/content/dam/Deloitte/co/Documents/audit/IFRS\%2015\% 20Productos\%20industriales\%20(ok).pdf

Equilibrium Calificadora de RiesgonS.A. (9 de Octubre de 2017). Alicorp S.A.A. Obtenido de Equilibrium: http://www.equilibrium.com.pe/Alicorpjun17.pdf

Equilibrium Clasificadora de Riesgo S.A. (2018, Setiembre 3). Retrieved from Equilibrium Clasificadora de Riesgo S.A.: http://www.equilibrium.com.pe/Alicorp.pdf

EY Peru. (2017). Estados financieros separados al 31 de diciembre de 2016 y de 2015 junto con el dictamen de los auditores independientes. Lima: EY Perú.

EY Perú. (2018). Estados financieros separados al 31 de diciembre de 2017 y 2016 junto con el dictamen de los auditores independientes. Lima: EY Perú.

International Accounting Standards Board. (Mayo de 2014). NIIF 15: Ingresos de Actividades Ordinarias Procedentes de Contratos con clientes. Londres. 


\section{BIBLIOGRAFÍA}

Alicorp. (2018). Memoria Anual 2016. Lima.

Banco Central de Reserva del Peru. (2018, Setiembre). Reporte de Inflacion - Panorama actual y proyecciones macroeconomicas 2018-2019. Lima, Lima, Peru.

Deloitte. (2017). Implementacion de la NIIF 15 Ingresos ordinarios derivados de contratos con clientes. 3. Retrieved from https://www2.deloitte.com/content/dam/Deloitte/co/Documents/audit/IFRS\%2015 $\% 20$ Productos\%20industriales\%20(ok).pdf

Equilibrium Calificadora de RiesgonS.A. (9 de Octubre de 2017). Alicorp S.A.A. Obtenido de Equilibrium: http://www.equilibrium.com.pe/Alicorpjun17.pdf

Equilibrium Clasificadora de Riesgo S.A. (2018, Setiembre 3). Retrieved from Equilibrium Clasificadora de Riesgo S.A.: http://www.equilibrium.com.pe/Alicorp.pdf

EY Peru. (2017). Estados financieros separados al 31 de diciembre de 2016 y de 2015 junto con el dictamen de los auditores independientes. Lima: EY Perú.

EY Perú. (2018). Estados financieros separados al 31 de diciembre de 2017 y 2016 junto con el dictamen de los auditores independientes. Lima: EY Perú.

International Accounting Standards Board. (Mayo de 2014). NIIF 15: Ingresos de Actividades Ordinarias Procedentes de Contratos con clientes. Londres. 
ANEXOS 


\title{
ANEXO 1: Estados financieros 2016 y 2015
}

\author{
ALICORP S.A.A. \\ Estado de Situación Financiera \\ Al 31 de diciembre de 2016 y 2015 \\ (En miles de soles)
}

Activo

Activo Corriente

Efectivo y equivalente de efectivo

Cuentas por cobrar comerciales, neto

Fondo de garantía para operaciones con derivados

Otras cuentas por cobrar, neto

2016
S/ 000

2015

S/ 000

Cuentas por cobrar a partes relacionadas

Anticipos a proveedores

155,058

15,175

Instrumentos financieros derivados

518,231

482,166

1,919

966

12,213

8,017

98,546

139,039

10,419

9,750

23,897

Inventarios, neto

374,300

522,384

Activos por impuesto a las ganancias

76,580

Otros activos no financieros

17,316

27,225

Activos clasificados como mantenidos para la venta, neto

35,248

24,087

Total Activo Corriente

$1,260,706$

$1,294,611$

Activo No Corriente

Otras cuentas por cobrar, neto

Instrumentos financieros derivados

14,244

12,674

Otros activos financieros

342

342

Cuentas por cobrar a partes relacionadas

165,759

Inversiones contabilizadas aplicando el método de participación

$2,387,302$

Propiedad, planta y equipo, neto

Activos intangibles, neto

$1,128,195$

$2,311,073$

117,246

$1,201,554$

117,519

Plusvalía

154,739

154,739

Total Activo No Corriente

$3,970,954$

$3,800,056$

Total Activo

$5,231,660$

$5,094,667$ 


\section{Pasivo}

Pasivo Corriente

Otros pasivos financieros

142,732

971,072

Cuentas por pagar comerciales

69,172

12,816

Cuentas por pagar a partes relacionadas

72,526

6,214

Instrumentos financieros derivados

13,489

Pasivos por impuestos a las ganancias

12,304

Provisiones

$1,300,325$

350,638

$1,064,767$

63,137

10,172

45,108

6,022

Total Pasivo Corriente

11,461

\section{Pasivo No Corriente}

Otros pasivos financieros

Otras cuentas por pagar

2,277

13,867

Beneficios a los empleados

74,133

1,687

Pasivos por impuestos a las ganancias diferidos

63,091

Total Pasivo No Corriente

$\mathbf{1 , 3 7 5 , 2 4 0}$

Total Pasivo

Patrimonio

Capital emitido

847,192

7,388

Acciones de inversión

169,438

Otras reservas de capital

$1,305,034$

Resultados acumulados

227,043

$2,894,458$

Otras reservas de patrimonio

2,556,095

$5,231,660$ 


\section{ALICORP S.A.A. \\ ESTADO DE RESULTADOS}

Por los años terminados a1 31 de diciembre de 2016 y de 2015

(En miles de soles)

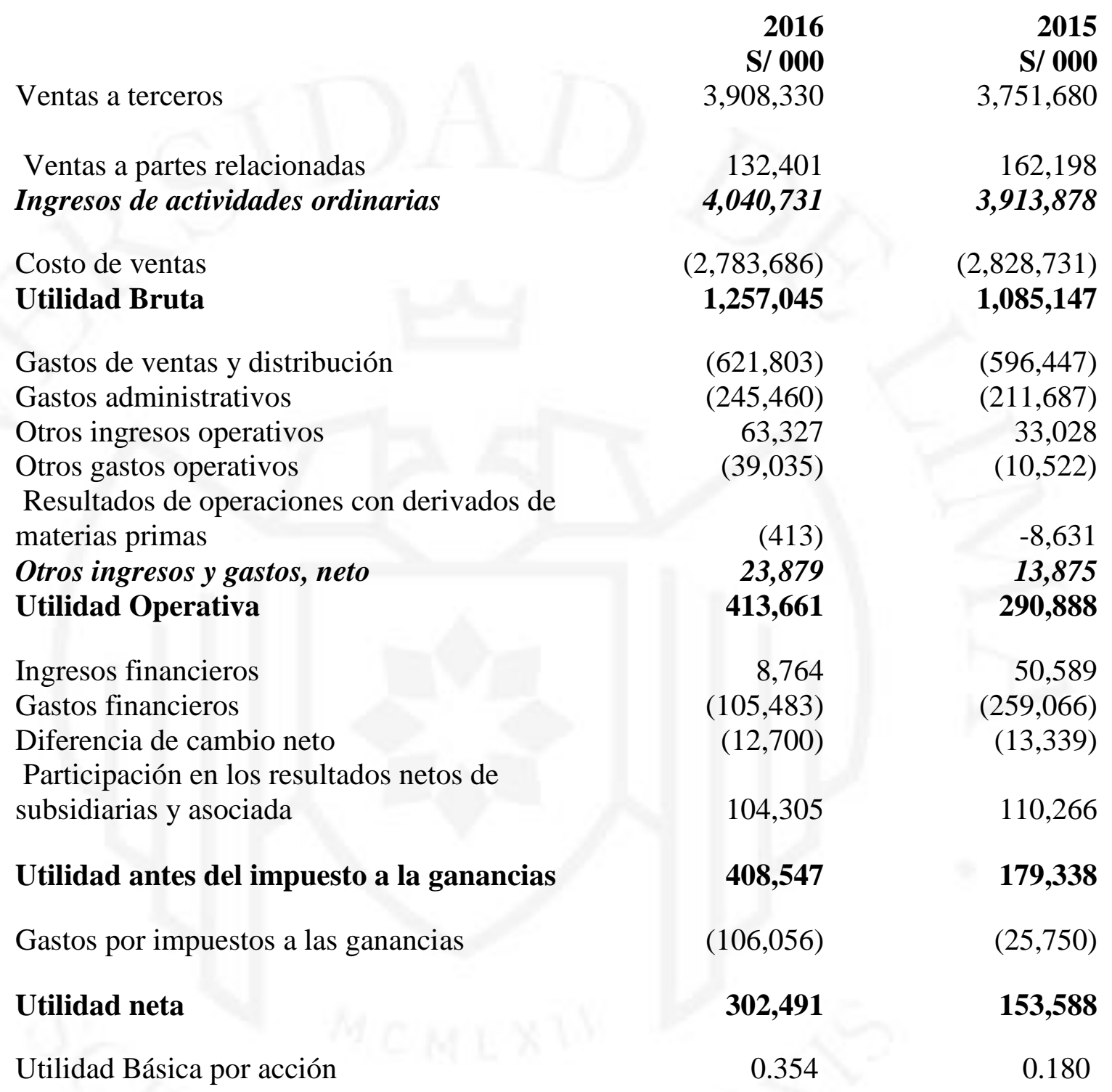




\section{ESTADO DE RESULTADOS}

Por los años terminados a1 31 de diciembre de 2017 y de 2016

(En miles de soles)

Ingresos operativos

$\%$ de aumento

Ganancia operativa

$\%$ de los ingresos

Ganancia neta del

ejercicio

$\%$ de los ingresos
31/12/2017 31/12/2016

$4,040,731 \quad 3,913,878$

$3.2 \%$

$413,661 \quad 290,888$

$10.2 \% \quad 7.4 \%$

$302,491 \quad 153,588$

$7.5 \% \quad 3.9 \%$ 


\title{
ANEXO 2: Estados financieros 2017 y 2016
}

\author{
ALICORP S.A.A. \\ Estado de Situación Financiera \\ Al 31 de diciembre de 2017 y 2016 \\ (En miles de soles)
}

Activo

Activo Corriente

Efectivo y equivalente de efectivo

2017

S/ 000

2016

$\mathrm{S} / 000$

Otros activos financieros

Cuentas por cobrar comerciales, neto

776,208

155,058

Fondo de garantía para operaciones con derivados

160,000

533,018

518,231

Otras cuentas por cobrar, neto

165

966

9,199

8,017

Cuentas por cobrar a partes relacionadas

141,665

139,039

Anticipos a proveedores

22,242

2,781

Instrumentos financieros derivados

5,534

Inventarios, neto

494,242

9,750

Activos por impuesto a las ganancias

Otros activos no financieros

21,044

374,300

Activos clasificados como mantenidos para la venta, neto

9,085

17,316

Total Activo Corriente

Activo No Corriente

Otras cuentas por cobrar, neto

1,883

3,127

Instrumentos financieros derivados

11,459

14,244

Otros activos financieros

342

342

Cuentas por cobrar a partes relacionadas

134,551

165,759

Inversiones contabilizadas aplicando el método de participación

$2,461,327$

$2,387,302$

Propiedad, planta y equipo, neto

$1,098,119$

$1,128,195$

Activos intangibles, neto

127,624

117,246

Plusvalía

154,739

154,739

Total Activo No Corriente

$3,990,044$

$3,970,954$

Total Activo

6,162,446

$5,231,660$ 
Pasivo

Pasivo Corriente

Otros pasivos financieros

$877,034 \quad 142,732$

Cuentas por pagar comerciales

$1,159,735 \quad 971,072$

Otras cuentas por pagar

$82,009 \quad 69,172$

Cuentas por pagar a partes relacionadas

$3,892 \quad 12,816$

Beneficios a los empleados

$90,247 \quad 72,526$

Instrumentos financieros derivados

Pasivos por impuestos a las ganancias

4,354

6,214

Provisiones

34,442

13,489

21,646

12,304

Total Pasivo Corriente

$\mathbf{2 , 2 7 3 , 3 5 9} \quad 1,300,325$

Pasivo No Corriente

Otros pasivos financieros

939,588

$1,287,621$

Otras cuentas por pagar

- $\quad 11,209$

Beneficios a los empleados

$3,722 \quad 2,277$

Pasivos por impuestos a las ganancias diferidos

62,091

74,133

Total Pasivo No Corriente

$1,005,401$

$1,375,240$

Total Pasivo

Patrimonio

Capital emitido

847,192

847,192

Acciones de inversión

7,388

7,388

Otras reservas de capital

170,227

169,438

Resultados acumulados

$1,638,488$

$1,305,034$

Otras reservas de patrimonio

220,391

227,043

Total Patrimonio

$\mathbf{2 , 8 8 3 , 6 8 6}$

2,556,095

Total Pasivo y Patrimonio

$6,162,446$

$5,231,660$ 


\section{ALICORP S.A.A. \\ ESTADO DE RESULTADOS \\ Por los años terminados a1 31 de diciembre de 2017 y de 2016}

(En miles de soles)

\begin{tabular}{|c|c|c|}
\hline & $\begin{array}{r}2017 \\
\text { S/ } 000\end{array}$ & $\begin{array}{r}2016 \\
\text { S/ } / 000 \\
908330\end{array}$ \\
\hline Ventas a terceros & $4,109,6 / 6$ & $3,908,330$ \\
\hline Ventas a partes relacionadas & 120,594 & 132,401 \\
\hline Ingresos de actividades ordinarias & $4,230,270$ & $4,040,731$ \\
\hline Costo de ventas & $(2,822,091)$ & $(2,783,686)$ \\
\hline Utilidad Bruta & $\mathbf{1 , 4 0 8 , 1 7 9}$ & $1,257,045$ \\
\hline Gastos de ventas y distribución & $(645,171)$ & $(621,803)$ \\
\hline Gastos administrativos & $(293,875)$ & $(245,460)$ \\
\hline Otros ingresos operativos & 45,261 & 63,327 \\
\hline Otros gastos operativos & $(26,302)$ & $(39,035)$ \\
\hline $\begin{array}{l}\text { Resultados de operaciones con derivados de materias } \\
\text { primas }\end{array}$ & $(8,290)$ & $(413)$ \\
\hline Otros ingresos y gastos, neto & 10,669 & 23,879 \\
\hline Utilidad Operativa & 479,802 & 413,661 \\
\hline Ingresos financieros & 43,460 & 8,764 \\
\hline Gastos financieros & $(99,074)$ & $(105,483)$ \\
\hline Diferencia de cambio neto & $(7,783)$ & $(12,700)$ \\
\hline $\begin{array}{l}\text { Participación en los resultados netos de subsidiarias } \\
\text { y asociada }\end{array}$ & 154,356 & 104,305 \\
\hline Utilidad antes del impuesto a la ganancias & 570,761 & 408,547 \\
\hline Gastos por impuestos a las ganancias & $(117,666)$ & $(106,056)$ \\
\hline Utilidad neta & 453,095 & 302,491 \\
\hline Utilidad Básica por acción & 0.530 & 0.354 \\
\hline
\end{tabular}


ESTADO DE RESULTADOS

Por los años terminados a1 31 de diciembre de 2017 y de 2016

(En miles de soles)

Ingresos operativos

$\%$ de aumento

Ganancia operativa

$\%$ de los ingresos

Ganancia neta del ejercicio

$\%$ de los ingresos
31/12/2017 31/12/2016

$4,230,270 \quad 4,040,731$

$4.7 \%$

$479,802 \quad 413,661$

$11.3 \% \quad 10.2 \%$

$453,095 \quad 302,491$

$10.7 \% \quad 7.5 \%$ 


\section{ANEXO 3: Indicadores Financieros}

\section{Indicadores Financieros}

$\underline{\text { Índices de liquidez }}$

$31 / 12 / 2017 \quad 31 / 12 / 2016 \quad 31 / 12 / 2015$

Prueba Corriente

0.96

0.97

0.83

Prueba Acida

0.73

0.65

0.48

$\underline{\text { Índices de solvencia }}$

Endeudamiento Patrimonial

1.14

1.05

1.32

Endeudamiento Patrimonial LP

0.35

0.54

0.61

Índices de Gestión

Rotación de inventarios o existencias

Días de venta por inventario

57.98

65.59

Rotación de cuentas por cobrar

8.05

8.08

8.10

Días de venta por cuentas por cobrar

44.73

44.56

44.44

\section{Índices de Rentabilidad}

Rentabilidad neta sobre Patrimonio

0.16

0.12

0.07

Rentabilidad neta sobre Ingresos

0.11

0.07

0.04 
ANEXO 4: Proyección Financiera 2018 - 2020

ALICORP S.A.A.

ESTADO DE RESULTADOS INTEGRALES

(En miles de soles)

2017

2019

2020

$\mathrm{S} / 000$

$\mathrm{S} / 000$

$\mathrm{S} / 000$

$\mathrm{S} / 000$

Ingresos de actividades ordinarias

$4,230,270$

$4,368,217$

$4,542,525$

$4,724,225$

Costo de ventas

$(2,822,091)$

$(3,113,051)$

$(3,199,031)$

$(3,321,088)$

Utilidad Bruta

$\mathbf{1 , 4 0 8 , 1 7 9}$

$\mathbf{1 , 2 5 5 , 1 6 6}$

$1,343,493$

$\mathbf{1 , 4 0 3 , 1 3 7}$

Gastos de ventas y distribución

$(645,171) \quad(434,084)$

$(541,535)$

Gastos administrativos

$(293,875)$

$(360,049)$

$(322,849)$

$(566,897)$

Resultados de operaciones con derivados

$(8,290)$

Otros ingresos y gastos, neto

$(7,346)$

18,959

22,059

Utilidad Operativa

$\mathbf{4 7 9 , 8 0 2}$

$\mathbf{4 7 5 , 7 4 6}$

$(6,000)$

21,541

$(337,067)$

Ingresos financieros

43,460

38,953

494,650

(5390)

19,842

$\mathbf{5 1 3 , 6 2 6}$

Gastos financieros

$(99,074)$

40,156

42,187

$(7,783)$

$(127,279)$

Diferencia de cambio neto

$(3,638)$

$(135,016)$

$(145,127)$

Participación en los resultados netos

de subsidiarias y asociada

154,356

100,496

0

0

Utilidad neta

570,761

484,278

399,790

410,687 


\section{Alicorp S.A.A. \\ Estado de Situación Financiera \\ (En miles de soles)}

\begin{tabular}{|c|c|c|c|c|}
\hline & $\begin{array}{c}2017 \\
\text { S/ } 000\end{array}$ & $\begin{array}{c}2018 \\
\text { S/ } 000\end{array}$ & $\begin{array}{c}2019 \\
\text { S/ } 000\end{array}$ & $\begin{array}{c}2020 \\
\text { S/ } 000\end{array}$ \\
\hline \multicolumn{5}{|l|}{ Activo } \\
\hline \multicolumn{5}{|l|}{ Activo corriente } \\
\hline Efectivo y equivalente de efectivo & 776,208 & 768,025 & 759,843 & 757,144 \\
\hline Otros activos financieros & 160,000 & - & - & - \\
\hline $\begin{array}{l}\text { Cuentas por cobrar comerciales, neto } \\
\text { Fondo de garantía para operaciones con } \\
\text { derivados }\end{array}$ & $\begin{array}{r}533,018 \\
165\end{array}$ & 610,320 & 659,524 & 594,304 \\
\hline Otras cuentas por cobrar, neto & 9,199 & 5,409 & 1,618 & 1,240 \\
\hline Cuentas por cobrar a partes relacionadas & 141,665 & 201,067 & 295,568 & 341,874 \\
\hline Anticipos a proveedores & 22,242 & 9,338 & 8,404 & 8,124 \\
\hline Instrumentos financieros derivados & 5,534 & - & - & - \\
\hline Inventarios, neto & 494,242 & 548,599 & 602,956 & 622,870 \\
\hline Otros activos no financieros & 21,044 & 14,704 & 11,028 & 10,109 \\
\hline $\begin{array}{l}\text { Activos clasificados como mantenido } \\
\text { para la venta, neto }\end{array}$ & 9,085 & 12,158 & 15,231 & 16,515 \\
\hline Total Activo corriente & $2,172,402$ & $2,169,620$ & $2,384,954$ & $2,352,180$ \\
\hline Activo no corriente & & & & \\
\hline Otras cuentas por cobrar, neto & 1,883 & 1,464 & 1045 & 945 \\
\hline Instrumentos financieros derivados & 11,459 & 10,493 & 9,968 & 9,802 \\
\hline Otros activos financieros & 342 & - & - & 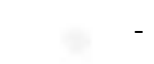 \\
\hline $\begin{array}{l}\text { Inversiones contabilizadas aplicando el } \\
\text { método de participación }\end{array}$ & $2,461,327$ & $3,459,259$ & $4,209,123$ & $4,601,975$ \\
\hline Propiedades, planta y equipo, neto & $1,098,119$ & $1,058,385$ & $1,026,633$ & $1,015,762$ \\
\hline Activos intangibles, neto & 127,624 & 136,940 & 146,257 & 149,573 \\
\hline Plusvalía & 154,739 & 154,739 & 154,739 & 154,739 \\
\hline Total Activo no corriente & $3,990,044$ & $4,899,040$ & $5,755,787$ & $6,157,460$ \\
\hline Total Activo & $6,162,446$ & $7,158,659$ & $8,109,960$ & $8,509,640$ \\
\hline
\end{tabular}




\section{Pasivo corriente}

Otros pasivos financiero

$\begin{array}{rrrr}877,034 & 900,999 & 924,964 & 933,164 \\ 1,159,735 & 1,409,258 & 1,658,780 & 1,756,681 \\ 82,009 & 44,439 & 28,885 & 25,515 \\ 3,892 & 72,599 & 105,269 & 121,060 \\ 90,247 & 85,777 & 82,346 & 81,248 \\ 4,354 & - & - & \\ 34,442 & 13,697 & 12,053 & 11,571 \\ 21,646 & 33,248 & 44,850 & 50,067 \\ \mathbf{2 , 2 7 3 , 3 5 9} & \mathbf{2 , 5 6 0 , 0 1 7} & \mathbf{2 , 8 5 6 , 1 0 9} & \mathbf{2 , 9 7 7 , 9 5 4}\end{array}$

Total Pasivo corriente

\section{Pasivo no corriente}

Otros pasivos financieros

Otras cuentas por pagar

Beneficios a los empleados

Total Pasivo no corriente

Total Pasivo

Patrimonio

Capital emitido

847,192

847,192

847,192

847,192

Acciones de inversión

Otras reservas de capital

170,227

167,468

162,444

160,820

Resultados acumulados

$1,638,488$

$1,915,311$

$2,192,135$

$2,297,746$

Otras reservas de patrimonio

220,391

178,441

135,615

124,766

Total Patrimonio

$2,883,686$

$3,115,800$

$3,344,774$

$3,437,911$

Total Pasivo y Patrimonio

$6,162,446$

$7,158,659$

$8,109,960$

$8,509,641$ 


\section{ANEXO 5: Indicadores Financieros de la proyección 2018 al 2020}

\section{Indicadores Financieros}

\section{Índices de liquidez}

Prueba Corriente

Prueba Acida

Índices de solvencia

Endeudamiento Patrimonial

Endeudamiento Patrimonial LP

\section{$\underline{\text { Índices de Gestión }}$}

Rotación de inventarios o existencias

Días de venta por inventario

Rotación de cuentas por cobrar

Días de venta por cuentas por cobrar
$31 / 12 / 2020 \quad 31 / 12 / 2019 \quad 31 / 12 / 2018$

$$
0.80
$$

0.82

0.86

0.58

0.61

0.63

$\begin{array}{lll}1.48 & 1.42 & 1.30 \\ 0.61 & 0.57 & 0.48\end{array}$

5.42

5.56

5.97

66.44

64.79

60.30

7.54

7.15

7.64

47.77

50.32

47.11

\section{$\underline{\text { Índices de Rentabilidad }}$}

Rentabilidad neta sobre Patrimonio

0.12

0.12

0.16

Rentabilidad neta sobre Ingresos

0.09

0.09

0.11 


\section{ANEXO 6: Flujo de Caja proyectado 2018 - 2020}

\begin{tabular}{|c|c|c|c|}
\hline Flujo de Caja Libre - Alicorp S.A.A. & $\begin{array}{c}2018 \\
\text { S/ } 000 \\
\end{array}$ & $\begin{array}{c}2019 \\
\text { S/ } 000 \\
\end{array}$ & $\begin{array}{c}2020 \\
\text { S/ } 000 \\
\end{array}$ \\
\hline Crecimiento & $3.6 \%$ & $3.6 \%$ & $3.6 \%$ \\
\hline Ingresos & $4,368,217$ & $4,542,525$ & $4,724,225$ \\
\hline EBIT & 453,624 & 471,726 & 490,595 \\
\hline Impuestos & 130,417 & 135,621 & 141,046 \\
\hline Utilidad Operativa después de Imp. & 323,207 & 336,104 & 349,549 \\
\hline (+) Depreciación y Amortización & 120,113 & 124,906 & 129,902 \\
\hline (-) Inversión en Capital de Trabajo & 27,417 & 2,934 & 3,059 \\
\hline Capital de Trabajo & 73,540 & 76,474 & 79,533 \\
\hline (-) CAPEX & 120,113 & 124,906 & 129,902 \\
\hline $\begin{array}{l}\text { Flujo de Caja Libre } \\
\text { Variación \% }\end{array}$ & 350,625 & $\begin{array}{r}\mathbf{3 3 3 , 1 7 0} \\
-4.98 \%\end{array}$ & $\begin{array}{r}346,490 \\
4.00 \%\end{array}$ \\
\hline
\end{tabular}

